UNIVERSIDADE DE BRASÍLIA (UNB)

FACULDADE DE ECONOMIA, ADMINISTRAÇÃO, CONTABILIDADE E CIÊNCIA DA INFORMAÇÃO E DOCUMENTAÇÃO (FACE)

HERMINIA LÚCIA SANTOS DE OLIVEIRA

\title{
VIABILIDADE DE IMPLANTAÇÃO DE UM MODELO DE UNIVERSIDADE CORPORATIVA NO PODER JUDICIÁRIO
}


HERMINIA LÚCIA SANTOS DE OLIVEIRA

\title{
VIABILIDADE DE IMPLANTAÇÃO DE UM MODELO DE UNIVERSIDADE CORPORATIVA NO PODER JUDICIÁRIO
}

\begin{abstract}
Monografia apresentada ao Programa de PósGraduação em Administração (PPGA) da Faculdade de Economia, Administração, Contabilidade e Ciência da Informação e Documentação (FACE), da Universidade de Brasília (UnB), como requisito parcial à obtenção do grau de Especialista em Gestão Judiciária.
\end{abstract}

Orientadora: Profa. Dra. Miramar Maia Ramos Vargas

\section{Brasília - DF}


Aos ao meu querido esposo Guilherme e nossos amados filhos Eduardo e Luiza, luzes da minha vida, dedico este trabalho com amor e carinho. 
Agradecimentos

A Deus, fonte maior de sabedoria.

Ao Superior Tribunal de Justiça por me propiciar a oportunidade de adquirir novos conhecimentos e assim, contribuir para meu crescimento profissional.

À minha orientadora, Prof. Dra. Miramar Ramos Maia Vargas por toda dedicação, paciência, carinho e cuidado para comigo durante nossa jornada.

Aos colegas de curso, pelo convívio e oportunidade de criação de laços afetivos, especialmente os componentes do grupo do qual eu participei, Ana Lucia Moraes de Souza, Apri Ramos, Edson Santos da Silva, Gilberto Ferreira Costa e José Fernando de Souza, pelo apoio mútuo.

Aos colegas Ana Lucia Oliveira Mota, Bárdia Tupy, Cláudia Beck, Ivan Gomes Bonifácio e Rosângela Silva, membros da comissão designada para elaborar o projeto deste curso, pelo empenho em viabilizar a sua consecução.

Aos meus filhos Eduardo e Luiza e meu esposo Guilherme, pela compreensão quando das ausências necessárias à conclusão deste trabalho.

Aos meus pais que, mesmo a distância, me incentivaram a correr atrás dos meus ideais.

Aos colegas de trabalho pela cooperação ao responder ao questionário de pesquisa e às entrevistas. 
“A educação é o único meio de preencher a lacuna entre onde estamos e aonde queremos chegar" 


\section{RESUMO}

O presente trabalho teve como objetivo geral investigar como estão sendo realizadas as atividades de treinamento e desenvolvimento em um Órgão do Poder Judiciário, verificando sua adequação às necessidades de aprendizagem das organizações no século XXI. O estudo está fundamentado em uma pesquisa exploratória, envolvendo a utilização da abordagem qualitativa e quantitativa, além de análise documental e foi realizada no Superior Tribunal de Justiça (STJ). A pesquisa qualitativa foi realizada por meio de entrevistas individuais semiestruturadas, com o objetivo de investigar a percepção de servidores e gestores sobre as mudanças ocorridas com a implantação do modelo de educação corporativa. Foram selecionados três grupos de sujeitos para participar dessas entrevistas: a) gestores estratégicos; b) servidores da área de gestão de pessoas e c) servidores que participam de ações educacionais disponibilizadas pelo Órgão. O resultado da análise das entrevistas apontou que os investigados perceberam mudanças favoráveis nas ações educacionais após a implantação da educação corporativa. Os dois primeiros grupos mostraram-se altamente favoráveis à utilização da Educação a Distância (EAD), tida como relevante para aumentar a acessibilidade dos servidores às ações educacionais. $\mathrm{O}$ terceiro grupo mostrou desconhecimento sobre as vantagens e a eficácia da EAD. Esse último resultado foi reforçado pelos resultados da pesquisa quantitativa, feita com a aplicação de um instrumento que buscou investigar a percepção dos servidores ocupantes de cargos comissionados lotados em gabinetes de ministro sobre a eficácia e vantagens da educação a distância. Participaram da pesquisa quantitativa um total de 199 sujeitos, dos quais 151 responderam ao questionário entregue, equivalendo a $60,64 \%$ da população investigada. Em relação às duas dimensões do instrumento aplicado, eficácia e vantagens, os dados apontam que os servidores não acreditam muito na eficácia, embora identifiquem algumas vantagens nessa modalidade de ensinoaprendizagem. Com relação à implantação de um modelo de universidade corporativa no STJ, foi observado que dos dez componentes fundamentais para o sucesso da universidade corporativa, a Instituição atende a cinco.

Palavras-chaves: Educação Corporativa, Universidade Corporativa, Educação a Distância, Mudança Organizacional. 


\section{LISTA DE FIGURAS}

Figura 1 - Dez componentes Fundamentais do Projeto de uma Universidade

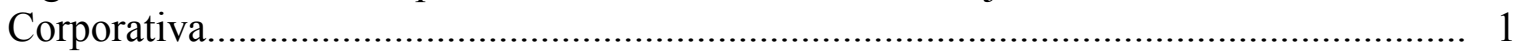
Figura 2 - Distribuição das Categorias-Sínteses por Grupos de Entrevistados.. 


\section{LISTA DE GRÁFICOS}

Gráfico 1 - Faixa etária dos Sujeitos da Pesquisa..................................................... 24

Gráfico 2 - Estado Civil dos Sujeitos da Pesquisa......................................................... 25

Gráfico 3 - Lotação dos Sujeitos da Pesquisa.................................................................. 25

Gráfico 4 - Escolaridade dos Sujeitos da Pesquisa..................................................... 26

Gráfico 5 - Tempo de Exercício no Tribunal dos Sujeitos da Pesquisa........................... 26

Gráfico 6 - Tipo de Vínculo dos Sujeitos da Pesquisa com a Organização...................... 27

Gráfico 7 - Tipo de Cargos Comissionados dos Sujeitos da Pesquisa............................ 27

Gráfico 8 - Tempo de Cargo Comissionado dos Sujeitos da Pesquisa.............................. 28 


\section{LISTA DE QUADROS}

Quadro 1 - Quadro de resultado de pesquisa realizada em 30 empresas

Quadro 2 - Quadro de autores brasileiros e suas abordagens sobre universidade corporativa

Quadro 3 - Matriz de Aprendizagem do Superior Tribunal de Justiça.

Quadro 4 - Educação Corporativa e Mudança Organizacional na percepção dos Gestores Estratégicos.

Quadro 5 - Educação Corporativa e Mudança Organizacional na percepção dos Servidores da Área de Desenvolvimento de Pessoas......................................................... 34

Quadro 6 - Educação Corporativa e Mudança Organizacional na percepção dos Servidores Participantes de Ações Educacionais.

Quadro 7 - Otimização na Educação Corporativa na percepção dos Gestores Estratégicos. 36

Quadro 8 - Otimização na Educação Corporativa na percepção dos Servidores da Área de Desenvolvimento de Pessoas.

Quadro 9 - Otimização na Educação Corporativa na percepção dos Servidores Participantes de Ações Educacionais.

Quadro 10 - Aceitação da Educação a Distância na percepção dos Gestores Estratégicos.

Quadro 11 - Aceitação da Educação a Distância na Percepção dos Servidores da Área de Desenvolvimento de Pessoas.

Quadro 12 - Aceitação da Educação a Distância na Percepção dos Servidores Participantes de Ações Educacionais.

Quadro 13 - Exemplos dos Itens da Dimensão "Eficácia da EaD”.

Quadro 14 - Exemplos dos Itens da Dimensão "Vantagens da EaD”. 


\section{LISTA DE TABELAS}

Tabela 1 - Sexo dos Sujeitos da Pesquisa............................................................... 24

Tabela 2 - Média e Desvio Padrão das Dimensões do Instrumento.................................. 41 


\section{SUMÁRIO}

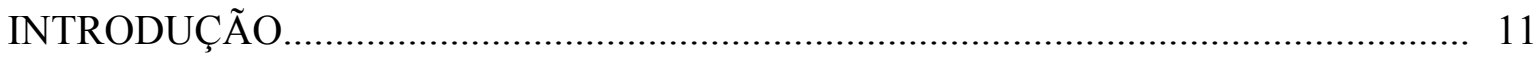

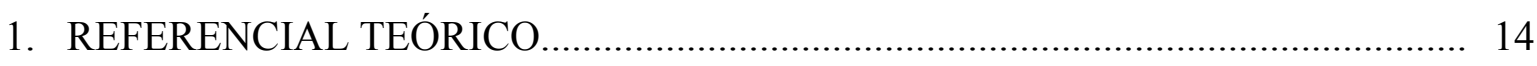

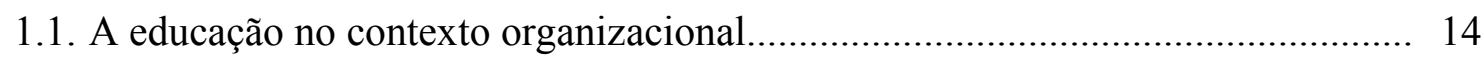

1.1.1. O Conceito de Educação.......................................................................... 14

1.1.2. Educação Continuada e Educação ao longo da vida................................. 14

1.1.3. Educação Corporativa e Universidade Corporativa................................ 15

1.2. Universidade corporativa: teoria e prática.................................................... 16

1.2.1. Construindo a universidade corporativa............................................... 16

1.2.2. Pesquisas sobre a universidade corporativa....................................... 18

1.2.3. A educação corporativa no serviço público............................................. 21

2. ASPECTOS METODOLÓGICOS DA PESQUISA................................................ 22

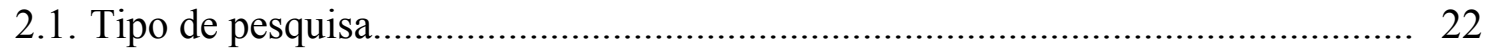

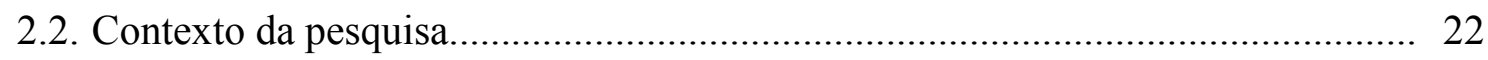

2.3. Participantes da pesquisa.......................................................................... 23

2.3.1. Pesquisa qualitativa...................................................................... 23

2.3.2. Pesquisa quantitativa.................................................................... 24

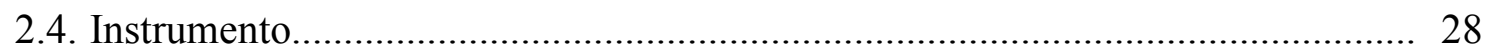

2.5. Procedimento de coleta de dados................................................................ 29

2.5.1. Pesquisa qualitativa............................................................................. 29

2.5.2. Pesquisa quantitativa.......................................................................... 29

2.6. Procedimento de análise dos dados.................................................................. 29

3. APRESENTAÇÃO E DISCUSSÃO DOS RESULTADOS...................................... 30

3.1. A educação corporativa no STJ na perspectiva da pesquisa qualitativa.............. 30

3.1.1. Educação corporativa e mudança organizacional.................................... 33

3.1.1.1.Grupo dos gestores estratégicos..................................................... 33

3.1.1.2.Grupo dos servidores da área de desenvolvimento de pessoas........... 34

3.1.1.3.Grupo dos servidores participantes de ações educacionais................. 34

3.1.2. Otimização da educação corporativa...................................................... 35

3.1.2.1. Grupo dos gestores estratégicos.................................................. 36

3.1.2.2. Grupo dos servidores da área de desenvolvimento de pessoas........... 36

3.1.2.3.Grupo dos servidores participantes de ações educacionais................. 37 
3.1.3. Educação a distância no STJ.................................................................. 38

3.1.3.1.Grupo dos gestores estratégicos................................................. 38

3.1.3.2.Grupo dos servidores da área de desenvolvimento de pessoas.......... 39

3.1.3.3.Grupo dos servidores participantes de ações educacionais................ 39

3.2. A educação a distância no STJ na perspectiva da pesquisa quantitativa............. 40

3.3. A educação corporativa STJ e os dez componentes fundamentais do projeto de uma universidade corporativa.................................................................. 42

3.3.1. Sistema de controle....................................................................... 43

3.3.2. Visão e missão................................................................................. 43

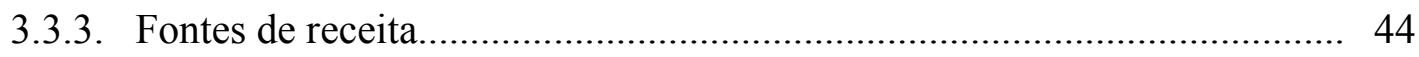

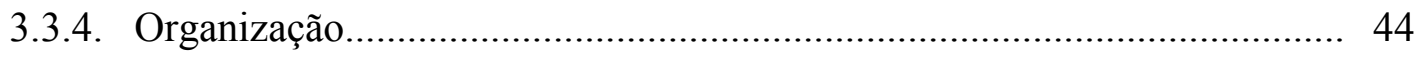

3.3.5. Partes interessadas.............................................................................. 45

3.3.6. Produtos e serviços........................................................................... 45

3.3.7. Parceiros de aprendizagem................................................................. 46

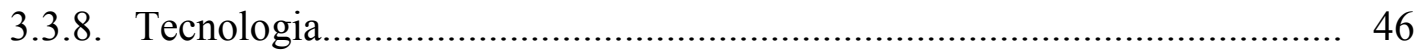

3.3.9. Avaliação...................................................................................... 47

3.3.10. Comunicação constante.................................................................... 48

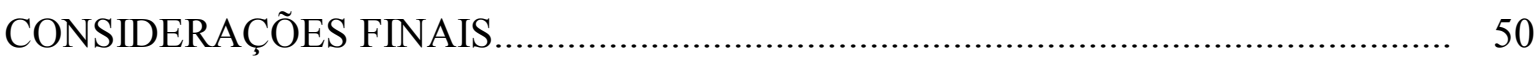

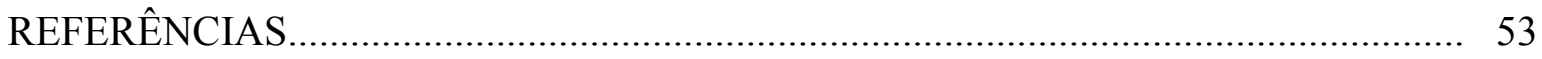

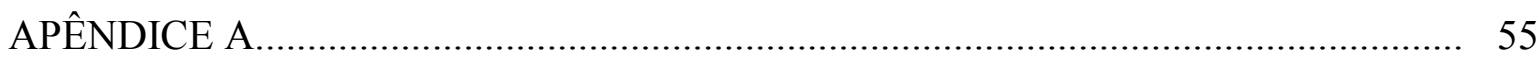

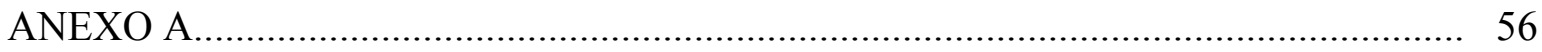

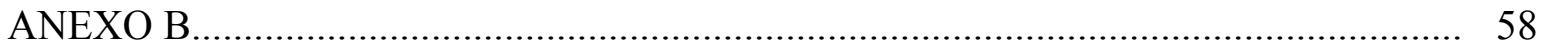

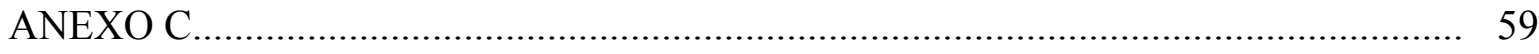

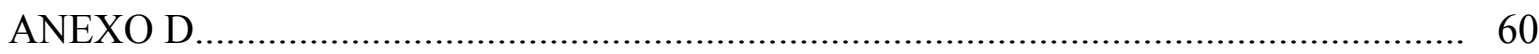




\section{INTRODUÇÃO}

Os servidores do Superior Tribunal de Justiça (STJ) recebem, desde o seu ingresso no quadro funcional, treinamentos que visam capacitá-los para o desenvolvimento de suas atividades nas unidades de trabalho. Esses eventos são programados pela Coordenadoria de Desenvolvimento de Pessoas (CDEP), da Secretaria de Gestão de Pessoas (SGP).

Até 2005 os eventos de Treinamento e Desenvolvimento (T\&D) eram definidos a partir do levantamento de necessidade de treinamento (LNT). O último LNT foi realizado em 2003, limitado à área judiciária, também denominada área-fim. Tendo em vista que esse levantamento não alcançou a área administrativa, as unidades que a compunham passaram a solicitar a realização de eventos de capacitação tendo por base o que julgava ser importante para o desempenho das suas atividades. Percebeu-se que deveria haver um alinhamento entre as ações de T\&D e a estratégia da organização. Assim, surgiu a necessidade de se rever todo esse processo.

Essa necessidade de revisão do modus operandi das áreas de treinamento e desenvolvimento de pessoal parece não ser específica no contexto judiciário. Uma análise da literatura mostra que as organizações contemporâneas estão introduzindo formas mais dinâmicas e abrangentes para suprir as necessidades de formação continuada.

De acordo com Éboli (2004) nas últimas décadas houve a necessidade da mudança de paradigma de uma administração baseada nas teorias tayloristas-fordistas, caracterizada por atividades padronizadas e centralizadas, para organizações mais flexíveis, na qual as mudanças são freqüentes e profundas. Essa mudança exigiu a evolução do modelo de T\&D, antes focado no escopo tático-operacional, para um modelo voltado ao desenvolvimento de atitudes, posturas e habilidades.

Ainda segundo Éboli, o grande marco dessa passagem da área tradicional de T\&D para uma preocupação mais ampla com a educação de todos os empregados foi a chegada do modelo de Universidade Corporativa (UC). Para a autora, é com a emergência da universidade corporativa que vem à tona a nova modalidade denominada de "Educação Corporativa".

Vargas e Abbad (2006) lembram, contudo, que embora os dois conceitos universidade corporativa e educação corporativa - tenham entrado ao mesmo tempo no contexto organizacional, nem toda organização precisa ou quer criar uma universidade corporativa. 
Para acompanhar esse cenário de mudanças, o Superior Tribunal de Justiça, em 2005, iniciou estudos para avaliar a viabilidade do STJ adotar um novo modelo de atuação para a área de desenvolvimento de pessoas. Esses estudos apontaram para um modelo de Educação Corporativa. Em 28 de fevereiro de 2007, por meio da Portaria $\mathrm{n}^{\mathrm{o}} 25$, foi instituída a Educação Corporativa do Superior Tribunal de Justiça. No ano de 2008, houve uma proposta de criação da Universidade Corporativa do Superior Tribunal de Justiça (UNIJUS), embora o projeto não tenha sido implementado, em razão de mudanças de gestão ocorridas no Tribunal.

É importante frisar que, desde 2005, o STJ tem buscado alinhar as ações educacionais à estratégia da organização. Entretanto, conforme afirma Vargas (2003), a adoção de uma nova estratégia para treinar e desenvolver empregados implica importantes mudanças no ambiente organizacional. No caso do Poder Judiciário, assim como em outras organizações, destaca-se a necessidade de um maior envolvimento dos gestores e servidores.

A necessidade de repensar as ações de treinamento e desenvolvimento de pessoal no âmbito do Superior Tribunal de Justiça levou a formulação do seguinte problema de pesquisa: "É viável a implantação de um modelo de Universidade Corporativa no Poder Judiciário?"

Para responder a essa questão foram estabelecidos os seguintes objetivos:

\section{Objetivo Geral}

- Investigar como estão sendo realizadas as atividades de treinamento e desenvolvimento no Superior Tribunal de Justiça (STJ), verificando sua adequação às necessidades de aprendizagem das organizações do século XXI.

\section{Objetivos Específicos}

- Revisar a literatura da área de treinamento e desenvolvimento de pessoal, com ênfase nos novos modelos de educação corporativa e universidade corporativa.

- Verificar se os servidores e gestores perceberam mudanças em relação às ações de treinamento, desenvolvimento e educação com a implantação do modelo de Educação Corporativa no STJ.

- Identificar a percepção dos servidores do STJ com relação ao uso da Educação a Distância como modalidade de ensino-aprendizagem. 
- Verificar se o modelo de Educação Corporativa do Superior Tribunal de Justiça atende às demandas de aprendizagem do Órgão ou se deveria evoluir para um modelo de Universidade Corporativa.

As corporações modernas têm se deparado com a necessidade de rever o modelo tradicional de T\&D e atrelar a capacitação à estratégia da organização e, assim, preparar o seu corpo funcional para o presente e, principalmente, o futuro. A literatura mais recente da área de gestão de pessoas tem relatado o uso de modelos de Educação Corporativa e de Universidade Corporativa por diferentes tipos de organizações. No setor público brasileiro, muitas dessas iniciativas ainda estão em fase de implantação. Estudar esse cenário educacional dentro do contexto do poder judiciário poderá contribuir para o aumento do conhecimento na área, bem como fornecer subsídios importantes para os órgãos interessados em adotar essas novas formas de aprendizagem que emergem hoje nas organizações.

A apresentação deste trabalho está organizada em três capítulos. O primeiro apresenta o referencial teórico, o segundo, os aspectos metodológicos da pesquisa empírica que foi realizada. No terceiro capítulo serão apresentados e discutidos os resultados encontrados na pesquisa. Por último, será feita a conclusão do trabalho. 


\section{CAPÍTULO 1 - REFERENCIAL TEÓRICO}

Neste Capítulo será apresentada uma breve revisão da literatura sobre o tema escolhido para a pesquisa. Inicialmente buscou-se definir os principais conceitos relativos ao tema. Para contextualizar historicamente o assunto, construiu-se uma linha do tempo, na qual foram elencados fatos que contribuíram para a evolução do desenvolvimento das pessoas no ambiente do trabalho. Em seguida, procurou-se apontar fatores considerados importantes para implantação do modelo de UC, além de pesquisas realizadas no Brasil sobre empresas privadas e públicas que optaram por adotá-lo e a produção acadêmica decorrente da investigação desses estudiosos. Por último e, não menos importante, situou-se a Educação Corporativa no serviço público.

\subsection{A educação no contexto organizacional}

\subsubsection{O Conceito de Educação}

A educação está presente na sociedade em todas as etapas da vida e a idéia de que o conhecimento só é adquirido no banco da escola já ficou para trás há muito tempo. Educação passou a fazer parte do cotidiano das organizações que buscam maximizar seus resultados por meio de investimentos em capacitação

O termo educação engloba ensinar e aprender. Éboli (2004) afirma que é por meio dela que o ser humano é formado e desenvolvido, a fim de perpetuar a cultura necessária a sua convivência em sociedade. A aprendizagem é um processo pelo qual ocorrem modificações no comportamento, de forma sistemática ou não, adquiridas pela experiência, observação ou prática.

Segundo Senge (2002) é pela aprendizagem que o indivíduo se recria, que descobre ser capaz de fazer algo que antes não era capaz de fazer. É bem mais que, simplesmente, internalizar informações ou adequar seu comportamento às atividades laborais.

\subsubsection{Educação Continuada e Educação ao Longo da Vida}

Vargas e Abbad (2006) buscaram estabelecer a diferença entre educação continuada e educação ao longo da vida, visto ser comum a utilização desses termos de forma indistinta. De 
acordo com Tight (1999 apud VARGAS; ABBAD, 2006) a educação continuada está mais relacionada com certificação, atualização e retreinamento, ao passo que educação ao longo da vida abrange toda a aprendizagem ocorrida durante a existência do ser humano.

A partir dessa diferenciação, esclarecem Vargas e Abbad (2006), torna-se claro que as organizações investem ou deveriam investir em educação continuada, como forma de ganhar vantagem competitiva e garantir sua existência, em contraponto à necessidade do indivíduo de aprender sempre em função de outras perspectivas que poderão se abrir para ele.

\subsubsection{Educação Corporativa e Universidade Corporativa}

Educação Corporativa para Vargas (2002) é um conceito que surgiu das mudanças ocorridas na arquitetura física e estratégica das organizações, causadas pela Revolução Tecnológica iniciada na metade do século XX.

Segundo Éboli (2004), as organizações sempre tiveram programas educacionais, entretanto, a clientela preferencial se restringia aos níveis gerenciais e a alta administração. Para os demais segmentos da organização utilizavam-se programas de treinamento, que visavam o desenvolvimento de habilidades mais específicas voltadas para a melhoria do desempenho no trabalho.

Ainda segundo Éboli, o surgimento do modelo de universidade corporativa foi o grande marco que fez a passagem da área tradicional de treinamento e desenvolvimento (T\&D) para uma preocupação com a educação de todos os funcionários, e não apenas de clientelas estratégicas da organização. Para a autora, o surgimento das universidades corporativas faz emergir a modalidade de educação corporativa.

Vargas e Abbad (2006) esclarecem que, apesar dos conceitos de Educação Corporativa e Universidade Corporativa terem sido inseridos concomitantemente no ambiente organizacional, a expressão "universidade corporativa" é muito restritiva, porque nem toda organização precisa ou vai criar esse tipo de unidade educacional em sua estrutura.

Com relação ao conceito de "universidade corporativa", uma das definições mais clássicas é a proposta por Meister (1999). Para a autora, universidade corporativa é uma unidade educacional criada para desenvolver e educar funcionários, clientes, fornecedores e comunidade, a fim de cumprir as estratégias empresariais da organização. Meister utiliza a metáfora do guarda-chuva para explicar que a universidade corporativa abriga todas as ações educacionais, sejam elas presenciais, semipresenciais ou a distância. 
De acordo com Meister (1999) a universidade corporativa não é um termo tão novo, pois a criação, em 1955, da Crotonville pela General Electric pode ser considerado o embrião dessas universidades. Ainda assim, o interesse pelo gerenciamento do aprendizado e desenvolvimentos dos empregados só foi intensificado nos Estados Unidos no fim dos anos 80. No Brasil, segundo Éboli (2004), esse conceito só começou a ser adotado a partir da década de 90, influenciado pela crescente globalização que demandava colaboradores mais capacitados e comprometidos com seu desenvolvimento contínuo.

Alperstedt (2000) propõe outra definição para universidade corporativa, caracterizada por se sustentar em três pilares: desenvolvimento de competências essenciais ao negócio, extensão das ações educacionais para além do seu corpo funcional e a parceria com instituições de ensino superior com vistas à validação de créditos cursados para fins de aferição de diploma ou sua chancela de forma independente.

Éboli (2004) afirma que a universidade corporativa é muito mais que um novo e simples modismo na área de gestão empresarial. Ela é um sistema de desenvolvimento de pessoas baseado na estratégia da empresa, que visa agregar valor ao resultado do negócio organizacional.

Entretanto, alguns estudiosos do tema lançam dúvidas sobre o que é realmente uma universidade corporativa. Para Dengo (2002), o modelo difundido pela imprensa especializada e pelos fóruns de Recursos Humanos no Brasil apresenta características diversas daquelas propostas por Meister (1999), com indícios mais fortes de modismos no campo de gestão. O autor ressaltou, ainda, que mesmo a adoção de modismos apresenta um lado positivo, qual seja, melhorar a imagem da organização e, conseqüentemente, auxiliar na venda de produtos e serviços.

\subsection{Universidade Corporativa: teoria e prática}

\subsubsection{Construindo a Universidade Corporativa}

Para Meister (1999), lançar uma universidade corporativa (UC) é um processo que envolve várias fases e demanda um certo tempo. No seu entendimento não é aconselhável pular fases sob pena de não permitir à organização consolidar a capacidade de aprendizagem dos seus colaboradores. Ainda segundo a autora, para o sucesso de uma UC são necessários dez componentes fundamentais (Figura 1), além do apoio da cúpula administrativa da organização. 


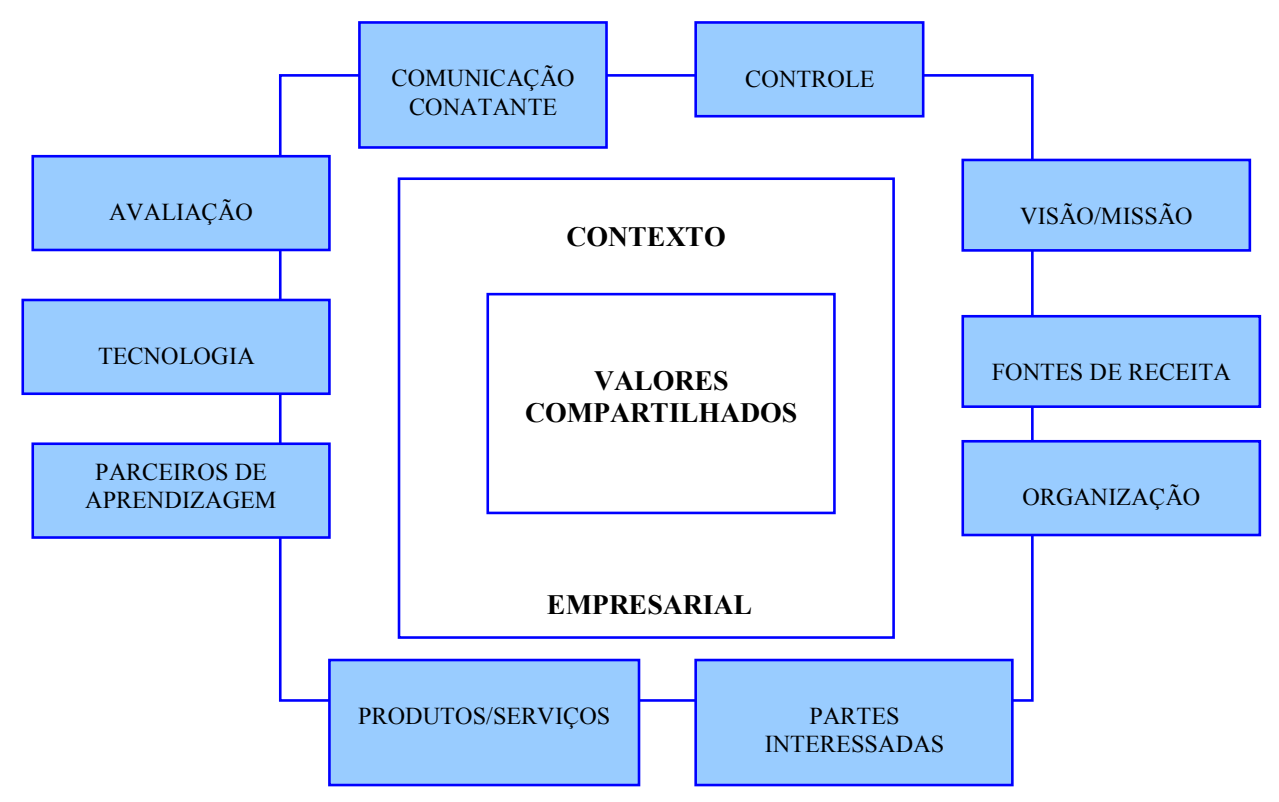

Figura 1 - Dez componentes Fundamentais do Projeto de uma Universidade Corporativa Fonte: Adaptado de Meister (1999, p. 63)

A adoção de sistema de educação no modelo de universidade corporativa é, para Éboli (2004), uma condição imprescindível para que as empresas desenvolvam com eficácia seus talentos humanos. A autora afirma, ainda, que a qualidade desse sistema depende da qualidade de seus idealizadores, que deve ser guiado pelos princípios:

- Competitividade;

- Perpetuidade;

- Conectividade;

- Disponibilidade;

- Cidadania;

- Parceria e

- Sustentabilidade.

Esses princípios são considerados como as bases filosóficas, ou seja, elementos conceituais importantes na constituição de um sistema de educação corporativa. Eles dão origem à elaboração de um plano estratégico consistente e de qualidade para atender as ações educacionais da organização.

Outro fator importante a ser considerado na adoção do modelo de universidade corporativa é a sua estrutura. Segundo Barley (2002 apud VARGAS, 2003) as melhores 
estruturas de universidade corporativa são aquelas que se harmonizam com as iniciativas e influências internas da organização, espelhando a cultura organizacional. Para a autora, a escolha do tipo de estrutura deve se basear em três grandes eixos: alinhamento corporativo, organização do conteúdo e estrutura interna.

\subsubsection{Pesquisas sobre Universidades Corporativas}

Diversos acadêmicos têm se dedicado a pesquisar o tema universidade corporativa no Brasil, como forma de descobrir que organizações estão adotando esse modelo, se aquelas que o adotaram o fazem de acordo com a literatura, e, que resultados estão sendo obtidos.

Éboli (2004) apresenta dados de pesquisa realizada em 2001 com 30 empresas que se destacam na área de Gestão de Pessoas no Estado de São Paulo (Quadro 1), visando a obtenção de informações sobre o modelo de educação corporativa existente nessas empresas:

Aproximadamente $60 \%$ das empresas adotaram um sistema de educação corporativa

$\checkmark$ A maioria das empresas (84\%) indicou que a estratégia, as diretrizes e as práticas de gestão de pessoas estão alinhadas ao negócio, o que contribui para a atração e retenção de talentos.

Em praticamente todas (94\%), os programas educacionais estão alinhados às estratégias do negócio.

$\checkmark$ Em quase $60 \%$ da empresas, os programas educacionais têm foco em competências.

$70 \%$ das empresas incentivam/subsidiam a participação de seus funcionários em programas de MBA e pósgraduação em instituições de ensino superior.

$\checkmark$ De $60 \%$ a 70\% adotaram múltiplos meios de aprendizagem (virtual e presencial) e estruturaram processos para criar oportunidades de aprendizagem contínua.

$\checkmark \quad$ Para as que implantaram uma UC, esta se revelou uma solução sob medida para o alinhamento da aprendizagem com as estratégias empresariais, e subverteu diversas práticas comuns aos tradicionais centros de T\&D, substituindo ações e programas estanques e esporádicos pelos de formação de longa duração.

Quadro 1 - Quadro de resultado de pesquisa realizada em 30 empresas Fonte: Adaptado de Éboli (2004)

A autora concluiu que as organizações que adotam os princípios da universidade corporativa favorecem a criação de sistemas de aprendizagem contínua, onde toda a empresa aprende e passa a entender a importância dessa aprendizagem estar vinculada à estratégica.

Marcondes e Paiva (2001) realizaram pesquisas em quatro instituições concluindo que o diferencial apresentado com a adoção da educação corporativa é menor do que seria esperado pelo que se difunde na literatura. Os autores ainda afirmam que haviam indícios dessas universidades pesquisadas serem departamentos de $T \& D$ revisitados, já que a maioria 
dos recursos e práticas tradicionais estavam sendo apresentados como 'renovados' dentro de um discurso de modernidade.

A partir desse estudo, os autores ressaltam que para fazer diferença, as organizações pesquisadas deveriam estar atuando em processo de gestão do conhecimento. Além disso, ressaltam a importância do envolvimento dos gerentes, como instrutores e partícipes do processo de ensino-aprendizagem, visto serem a cultura, os valores e as atitudes, componentes fundamentais da educação corporativa.

Brandão (2006) investigou a abordagem dada por autores brasileiros sobre universidade corporativa. Para a autora, as iniciativas de implantação de UC resultaram no aumento de produção acadêmica sobre o tema (Quadro 2). Desse trabalho, restou revelada que, no contexto brasileiro, a realidade empírica ainda está pouco próxima do seu escopo conceitual. A autora enfatiza, ainda, a necessidade de compreender e discernir mais cuidadosamente sobre o tema levando em consideração o pouco tempo de amadurecimento das iniciativas de universidade corporativa no Brasil e sua pouca consistência teóricoconceitual .

\begin{tabular}{|c|c|c|c|}
\hline AUTOR & OBJETIVO & METODOLOGIA & RESULTADOS ENCONTRADOS \\
\hline 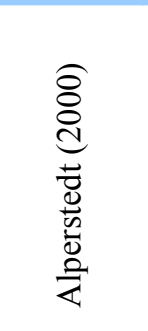 & $\begin{array}{l}\text { Propor definição para as UCs, a } \\
\text { partir de critérios de diferenciação } \\
\text { dos T\&Ds. }\end{array}$ & $\begin{array}{l}\text { Artigo teórico- } \\
\text { conceitual: pesquisa } \\
\text { bibliográfica }\end{array}$ & $\begin{array}{l}\text { Definição propõe características } \\
\text { concomitantes: } \\
\text { - desenvolvimento de competências } \\
\text { essenciais ao negócio; } \\
\text { - extensão dos serviços à cadeia de } \\
\text { valor; } \\
\text { - parcerias com instituições de ensino } \\
\text { superior }\end{array}$ \\
\hline 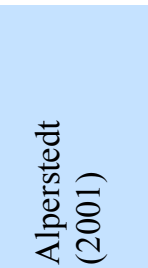 & $\begin{array}{l}\text { Identificar a representação das UCs } \\
\text { para as instituições de ensino } \\
\text { superior: concorrência potencial ou } \\
\text { oportunidades estratégicas? }\end{array}$ & $\begin{array}{l}\text { Pesquisa qualitativa } \\
\text { exploratória; estudo } \\
\text { de casos: } 4 \text { UCs } \\
\text { brasileiras e } 3 \text { UCs } \\
\text { americanas. }\end{array}$ & $\begin{array}{l}\text { As UCs representativas de } \\
\text { concorrência para áreas como: } \\
\text { administração, engenharia e ciências } \\
\text { da informação, especialmente em } \\
\text { cursos de pós-graduação e outros } \\
\text { segmentos do público adulto. }\end{array}$ \\
\hline 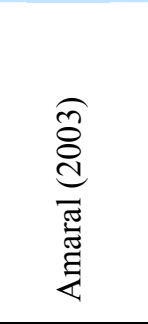 & $\begin{array}{l}\text { Construir um quadro de referência } \\
\text { teórico-prático sobre EC, para fins } \\
\text { de instrumento de avaliação. } \\
\text { Identificar políticas e práticas que } \\
\text { representem a valorização da EC, } \\
\text { em suas múltiplas demandas. }\end{array}$ & $\begin{array}{l}\text { Pesquisa qualitativa } \\
\text { exploratória; estudo } \\
\text { de caso. }\end{array}$ & $\begin{array}{l}\text { Referências teórico-práticas } \\
\text { propostas de EC em seis dimensões. } \\
\text { Em ternos de práticas e políticas, a } \\
\text { visão sobre educação corporativa e } \\
\text { simplificada e parcial; o processo de } \\
\text { gestão, fragmentado, com visão } \\
\text { estratégica e de totalidade em } \\
\text { construção. }\end{array}$ \\
\hline
\end{tabular}




\begin{tabular}{|c|c|c|c|}
\hline 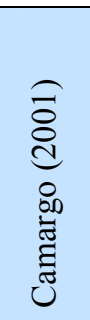 & $\begin{array}{l}\text { Identificar os } \text { aspectos mais } \\
\text { significativos da contribuição dos } \\
\text { programas de UC para o } \\
\text { desenvolvimento de competências } \\
\text { individuais de gestores. }\end{array}$ & $\begin{array}{l}\text { Pesquisa qualitativa } \\
\text { descritiva; estudo } \\
\text { de caso. }\end{array}$ & $\begin{array}{l}\text { Identificar contribuições significativas } \\
\text { da UC; construiu modelo de prestação } \\
\text { de serviços no setor; identificou as } \\
\text { competências individuais necessárias. } \\
\text { A UC como veículo positivo de } \\
\text { desenvolvimento de competências } \\
\text { gerenciais. }\end{array}$ \\
\hline 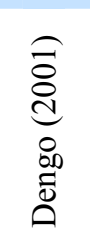 & $\begin{array}{l}\text { Identificar as bases teórico- } \\
\text { empíricas que sustentam o modelo } \\
\text { de UC, verificando seu alinhamento } \\
\text { com o conceito proposto por } \\
\text { Meister (1999). }\end{array}$ & $\begin{array}{l}\text { Pesquisa qualitativa } \\
\text { exploratória; estudo } \\
\text { de caso. }\end{array}$ & $\begin{array}{l}\text { As UCs nos moldes dos centros de } \\
\text { T\&D; distantes do conceito de Meister } \\
\text { (1999); configurando-se como } \\
\text { modismo e não como inovação. }\end{array}$ \\
\hline 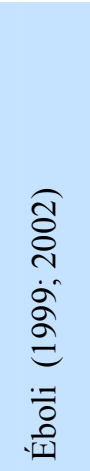 & $\begin{array}{l}\text { Estudar as experiências de UC no } \\
\text { Brasil, construindo análise ampla } \\
\text { sobre o tema e suas interfaces com } \\
\text { o ensino superior. }\end{array}$ & $\begin{array}{l}\text { Pesquisa } \\
\text { bibliográfica e de } \\
\text { campo. }\end{array}$ & $\begin{array}{l}\text { Pesquisa em andamento. Produções: } \\
\text { - coletânea sobre UC no Brasil; } \\
\text { - identificação de UCs no Brasil: quais } \\
\text { e quantas; } \\
\text { - orientações para conceber e } \\
\text { implantar siste4mas educacionais; } \\
\text { - análise da UC incluindo interface } \\
\text { com instituições de ensino superior e } \\
\text { com gestão do conhecimento; } \\
\text { - artigos em revistas, livros, } \\
\text { periódicos. }\end{array}$ \\
\hline : & $\begin{array}{l}\text { Comparar o modelo de T\&D do } \\
\text { Grupo Gerdau e o modelo da } \\
\text { Unialgar - Grupo Algar. }\end{array}$ & $\begin{array}{l}\text { Pesquisa qualitativa } \\
\text { descritiva; estudo } \\
\text { de caso. }\end{array}$ & $\begin{array}{l}\text { Tendência de a unidade de T\&D de o } \\
\text { Grupo Gerdau evoluir para modelo de } \\
\text { UC. }\end{array}$ \\
\hline 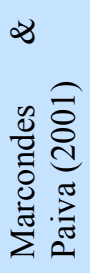 & $\begin{array}{l}\text { Identificar a diferença de concepção } \\
\text { e atuação entre UC e T\&D. }\end{array}$ & $\begin{array}{l}\text { Pesquisa qualitativa } \\
\text { exploratória; estudo } \\
\text { de caso. }\end{array}$ & $\begin{array}{l}\text { Preocupação com desenvolvimento de } \\
\text { competências individuais e gerenciais; } \\
\text { maior alinhamento às estratégias } \\
\text { corporativas são os principais pontos } \\
\text { inovadores em relação ao T\&D. } \\
\text { Outros impasses são mantidos. }\end{array}$ \\
\hline 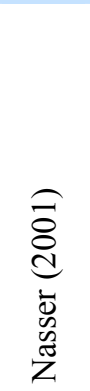 & $\begin{array}{l}\text { A partir da ótica da UC, busca } \\
\text { informação e discute a metodologia } \\
\text { adotada pela UC e o papel da } \\
\text { informação nesse processo.q }\end{array}$ & $\begin{array}{l}\text { Pesquisa qualitativa } \\
\text { descritiva; estudo } \\
\text { de caso. }\end{array}$ & $\begin{array}{l}\text { Relevância do papel da informação } \\
\text { nas UCs. Identifica práticas } \\
\text { educacionais em que a informação e o } \\
\text { conhecimento são considerados fatores } \\
\text { estratégicos e diferenciais } \\
\text { competitivos. Revela o conceito de } \\
\text { aprendizagem sob demanda e suas } \\
\text { práticas alinhadas ao mapa de } \\
\text { competências das empresas estudadas. }\end{array}$ \\
\hline 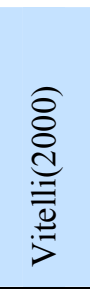 & $\begin{array}{l}\text { Questionar a UC como fonte de } \\
\text { vantagem competitiva e de criação } \\
\text { de ambiente de aprendizagem. }\end{array}$ & $\begin{array}{l}\text { Artigo teórico- } \\
\text { conceitual: pesquisa } \\
\text { bibliográfica. }\end{array}$ & 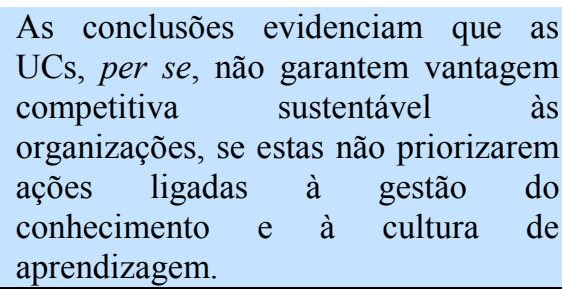 \\
\hline
\end{tabular}

Quadro 2 - Quadro de autores brasileiros e suas abordagens sobre universidade corporativa Fonte: Brandão (2006) 


\subsubsection{A Educação Corporativa no Serviço Público}

Segundo Éboli (2004), algumas organizações públicas já adotaram o modelo de universidade corporativa. Dentre estas, destacam-se: Banco do Brasil, Sabesp e Empresa Brasileira de Correios e Telégrafos:

- Universidade Corporativa Banco do Brasil - Foi lançada oficialmente em 2002, tendo como meta principal desenvolver a excelência humana e profissional dos funcionários por meio da criação de valor em soluções educacionais. Além disso, espera-se que os funcionários a enxerguem como um importante espaço de desenvolvimento pessoal e profissional.

- Universidade Empresarial SABESP - Criada em 2000, para promover a educação contínua da cadeia de valor, como forma de desenvolver as competências consideradas essenciais para que os desafios empresariais fossem viabilizados é o seu objetivo.

- Universidade Correios - Tem como objetivos capacitar pessoal, elevar a imagem da marca da ECT, além de facilitar os contatos com os diversos parceiros.

Observa-se que há várias organizações públicas que já adotaram o modelo de Universidade Corporativa e a tendência atual é que muitas outras venham a migrar do T\&D tradicional. Percebe-se, entretanto, que essa mudança não ocorre com a mesma velocidade que em empresas privadas.

Com relação ao Poder Judiciário, foi feita uma pesquisa usando-se o site de busca "Google" para identificar os órgãos que implantaram o modelo de Universidade Corporativa. Os resultados mostraram que, em 2007, foi criada a Unicorp (Universidade Corporativa da Justiça Federal da $1^{\text {a }}$ Região) com a finalidade de planejar, implantar e expandir sistema integrado de educação corporativa alinhado às diretrizes e objetivos estratégicos do Tribunal. Seguindo esta tendência, verificou-se que o Tribunal de Justiça do Estado da Bahia, Tribunal de Justiça do Distrito Federal e Territórios e o Tribunal de Justiça do Estado de Santa Catarina também adotaram esse modelo. Por serem iniciativas recentes, não foram encontradas citações em trabalhos acadêmicos a respeito dessas experiências. 


\section{CAPÍTULO 2 - ASPECTOS METODÓLOGICOS DA PESQUISA}

\subsection{Tipo de Pesquisa:}

Para a realização da pesquisa adotou-se a taxonomia proposta por Vergara (2007) que utiliza dois critérios básicos para sua classificação: quanto aos fins e quanto aos meios.

Quanto aos fins, a investigação utilizada neste trabalho é do tipo exploratória, visto que a organização estudada necessita de maior produção de conhecimento acumulado e sistematizado para viabilizar a implantação, com sucesso, do modelo de universidade corporativa.

Quanto aos meios, foi realizada pesquisa bibliográfica e documental. Bibliográfica, para embasar a fundamentação teórica e metodológica desse trabalho, buscando explorar assuntos relacionados à educação nas organizações e documental porque foram analisados documentos internos da Instituição pesquisada.

A pesquisa adotou, também, as duas abordagens - qualitativa e quantitativa.

\subsection{Contexto da Pesquisa}

A pesquisa foi realizada no Superior Tribunal de Justiça (STJ), instituição Pública de Direito Público, com sede na Capital Federal.

A Constituição de 1988 criou o STJ e sua instalação ocorreu em 7 de abril de 1989 em cumprimento à Lei ${ }^{\circ}$ 7.746/89, em Sessão Solene, especialmente convocada, pelo Supremo Tribunal Federal (STF).

O STJ absorveu o Tribunal Federal de Recursos e parte da extinta competência do STF, que passou a atuar precipuamente na guarda da Constituição Federal. Ele é o órgão de cúpula da justiça comum e tem jurisdição em todo o território nacional, sobre a justiça estadual e Federal não especializada. É uma corte constitucional que tem por missão manter permanentemente o controle da legalidade, isto é, a correta interpretação e aplicação do direito federal, nos julgados dos tribunais locais, de última ou única instância, em caráter definitivo. O STJ tem a função de zelar pela uniformidade do direito federal em todo o território nacional e sua competência está disposta na Constituição.

A composição inicial do STJ deu-se pelo aproveitamento dos então atuais Ministros do Tribunal Federal de Recursos. O número de Ministros necessário à complementação dos trinta 
e três estabelecidos pela Constituição foram indicados em listas tríplices pelo extinto Tribunal. Assim, o STJ compõe-se de trinta e três Ministros que são nomeados pelo Presidente da República, escolhidos dentre brasileiros com mais de trinta e cinco e menos de sessenta e cinco anos, de notável saber jurídico e reputação ilibada, sendo a escolha submetida à aprovação do Senado Federal.

De acordo com informações prestadas pela Seção de Provimento da Coordenadoria de Provimento e Informações Funcionais, em 5/9/2008, o quadro funcional do STJ era composto de 2.625 cargos efetivos, dos quais 988 de nível superior, 1.636 de nível intermediário e um de nível auxiliar, distribuídos nas áreas judiciária, administrativa e gabinetes de Ministros.

\subsection{Participantes da Pesquisa}

\subsubsection{Pesquisa Qualitativa}

A pesquisa qualitativa envolveu a participação de seis sujeitos distribuídos em três grupos:

$\checkmark$ Grupo 1 - Formado por dois gestores estratégicos que atuam nos programas de aprendizagem que integram a Educação Corporativa do Superior Tribunal de Justiça. Esses gestores são responsáveis por definir as ações educacionais a partir do Plano de Gestão do Órgão.

$\checkmark$ Grupo 2 - Formado por dois servidores da área de Gestão de Pessoas, responsáveis por viabilizar as ações definidas pelos gestores estratégicos.

$\checkmark$ Grupo 3 - Formado por dois servidores que participam das ações educacionais disponibilizadas pelo Órgão.

O critério de seleção dos sujeitos foi feito com base na representação qualitativa dos grupos que atuam no processo de educação corporativa do STJ. Do total de participantes, dois eram do sexo masculino e quatro do sexo feminino. 


\subsubsection{Pesquisa Quantitativa}

A pesquisa quantitativa abrangeu somente os ocupantes de cargos comissionados lotados em todos os gabinetes de ministros e no Gabinete da Secretaria-Geral da Presidência, perfazendo um total de 32 unidades investigadas.

A população desse segmento organizacional atinge um total de 249 servidores. Desse quantitativo foram distribuídos 199 questionários, totalizando 79,92\% da população investigada. Dos 199 questionários distribuídos foram respondidos 151, o que equivale a $60,64 \%$ da população. O perfil demográfico dos participantes da pesquisa quantitativa será descrito a seguir:

\section{A) Sexo}

Tabela 1 - Sexo dos Sujeitos da Pesquisa

\begin{tabular}{|l|c|c|}
\hline \multicolumn{1}{|c|}{ Sexo } & f & \% \\
\hline Feminino & 66 & 43,7 \\
\hline Masculino & 80 & 53,0 \\
\hline Dado Ausente & 5 & 3,3 \\
\hline \multicolumn{1}{|c|}{ Total } & $\mathbf{1 5 1}$ & $\mathbf{1 0 0 , 0}$ \\
\hline
\end{tabular}

Os dados da Tabela 1 demonstram que a maior parte dos participantes da pesquisa $(53,0 \%)$ pertence ao sexo masculino. As mulheres responderam por 43,7\% de participação na pesquisa. Cinco pessoas deixaram de informar esse dado no questionário.

\section{B) Faixa Etária}

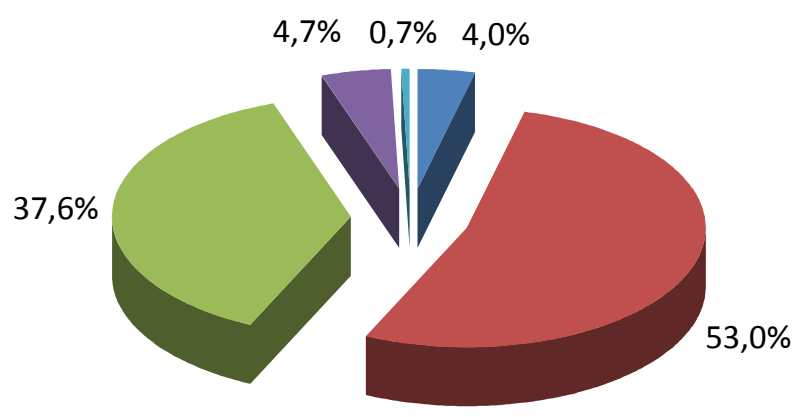

\footnotetext{
Menos de 25 anos

De 26 a 35 anos

De 36 a 45 anos

De 46 a 55 anos

Acima de 55 anos
}

Gráfico 1 - Faixa etária dos Sujeitos da Pesquisa 
Os dados do Gráfico 1 revelam que 53\% dos respondentes se encontra na faixa etária de 26 a 35 anos, o que corresponde a 79 sujeitos, enquanto que os participantes com idade superior a 55 anos é de $0,7 \%$. Duas pessoas não informaram esse dado.

\section{C) Estado Civil}

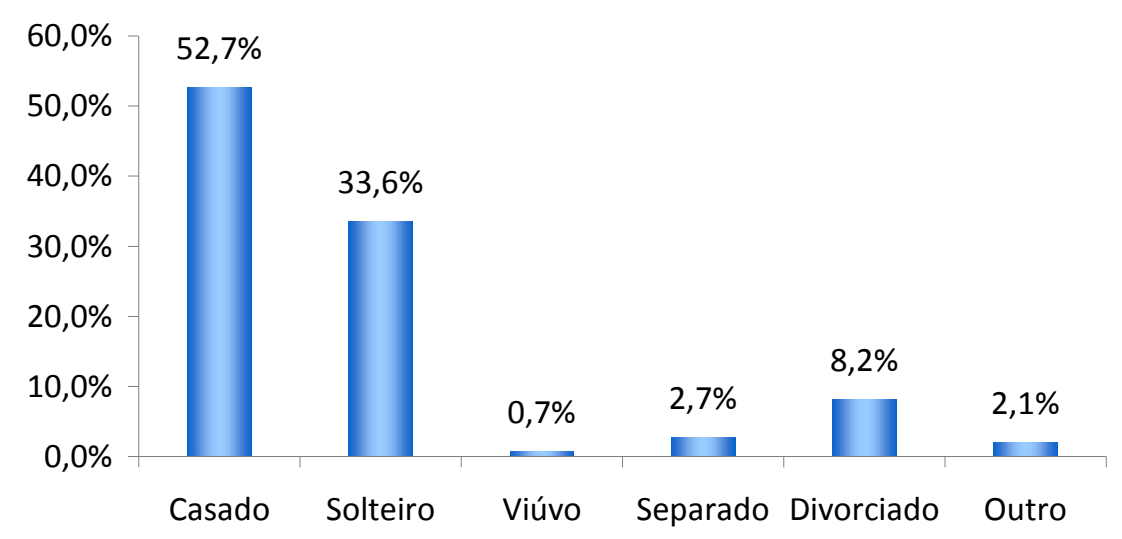

Gráfico 2 - Estado Civil dos Sujeitos da Pesquisa

Com relação ao estado civil dos participantes da pesquisa, os dados do Gráfico 2 demonstram que a maior parte $(52,7 \%)$ é casada. Cinco pessoas deixaram de informar esse dado no questionário.

\section{D) Lotação}

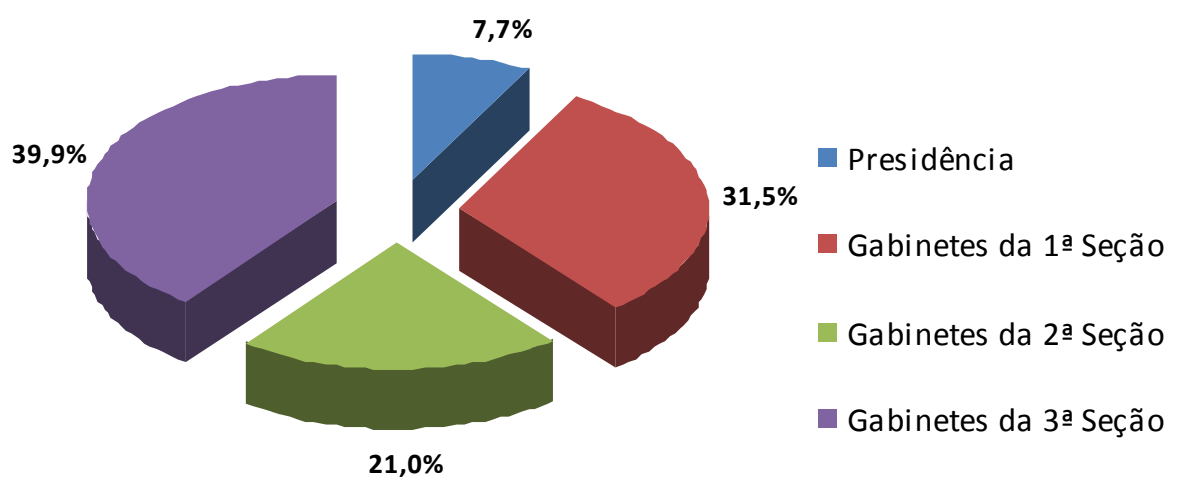

Gráfico 3 - Lotação dos Sujeitos da Pesquisa

Os dados do Gráfico 3 apontam que 39,9\% dos participantes estão lotados em Gabinetes da $3^{\text {a }}$ Seção, enquanto que 7,7\% trabalham na Presidência do STJ. 


\section{E) Escolaridade}

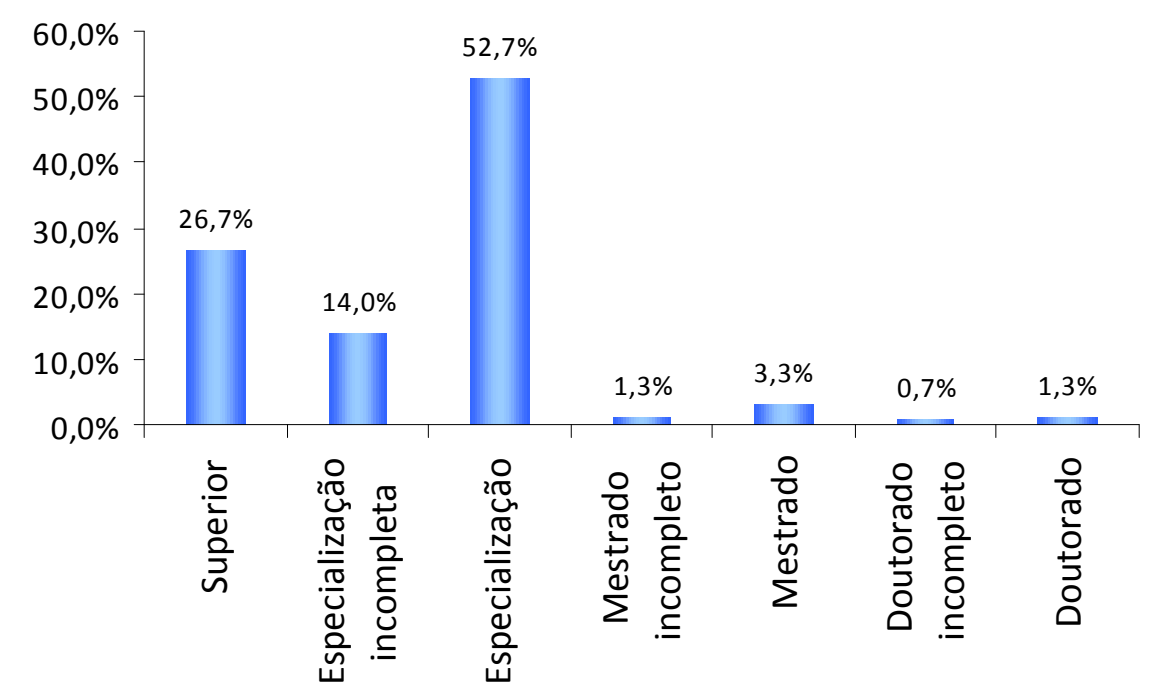

Gráfico 4 - Escolaridade dos Sujeitos da Pesquisa

No STJ, a ocupação de Cargo Comissionado em Gabinete de Ministro está condicionada à escolaridade mínima de nível superior. Os dados do Gráfico 4 revelam que mais da metade dos participantes da pesquisa concluíram, também, uma pós-graduação, sendo que 52,3\% possui Especialização, 3,3\% Mestrado e 1,3\% Doutorado.

\section{F) Tempo de Exercício no Tribunal}

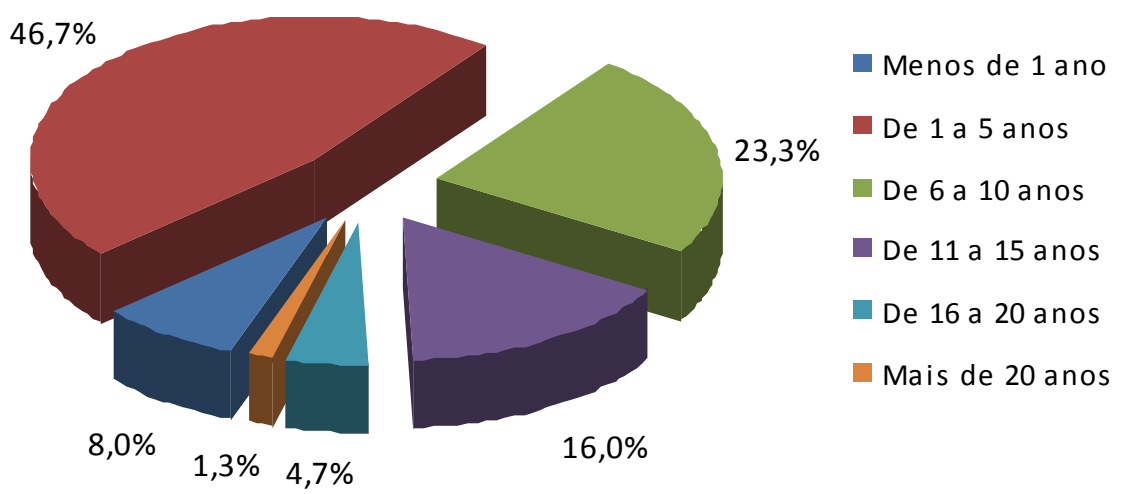

Gráfico 5 - Tempo de Exercício no Tribunal dos Sujeitos da Pesquisa

Os dados do Gráfico 5 apontam que 46,4\% dos respondentes possuem entre 1 e 5 anos de tempo de exercício no Órgão. Somando-se o percentual de menos de 1 ano com o percentual de 1 a 5 anos, observa-se que mais da metade (54,7\%) trabalham, no máximo, há 
cinco anos na Instituição. Esse dado sinaliza que, entre os participantes da pesquisa, prevalecem pessoas com pouco tempo de serviço no STJ.

\section{G) Tipo de Vínculo com a Organização}

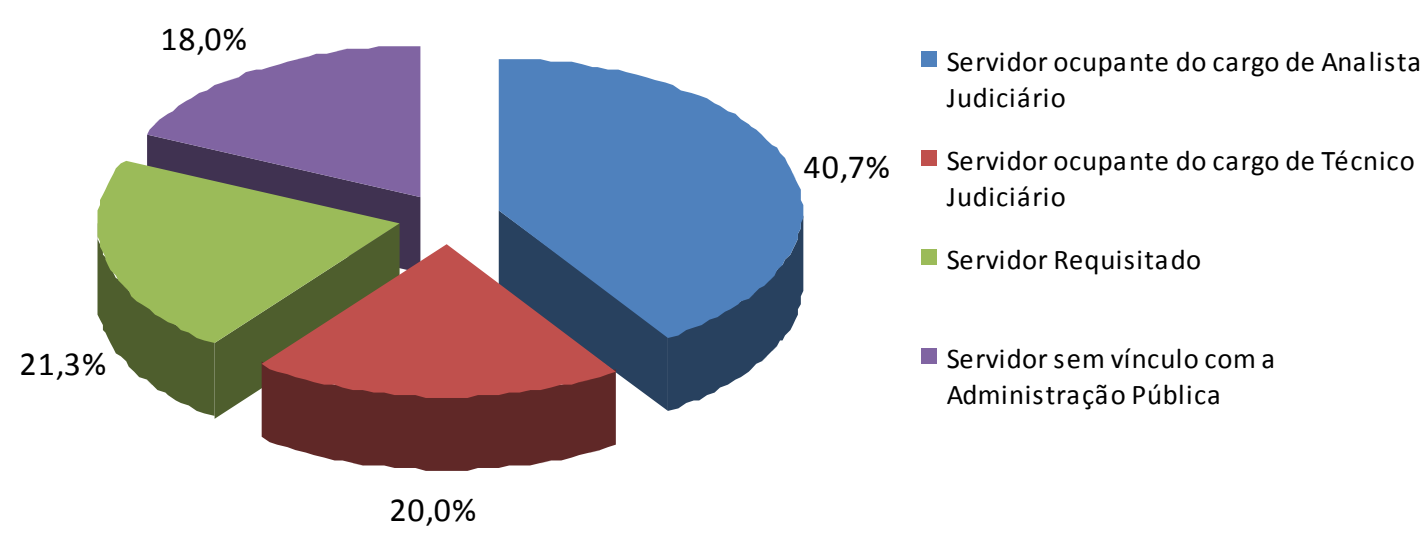

Gráfico 6 - Tipo de Vínculo dos Sujeitos da Pesquisa com a Organização

No grupo pesquisado, conforme mostra o Gráfico 6, observa-se que a maior parte dos respondentes são servidores efetivos do Quadro de Pessoal do STJ, sendo 40,7\% Analistas Judiciários e 19,9\% Técnicos Judiciários. O menor percentual encontrado foi de 17,9\% relativos a servidores sem vínculo com a Administração Pública.

\section{H) Tipo de Cargo Comissionado}

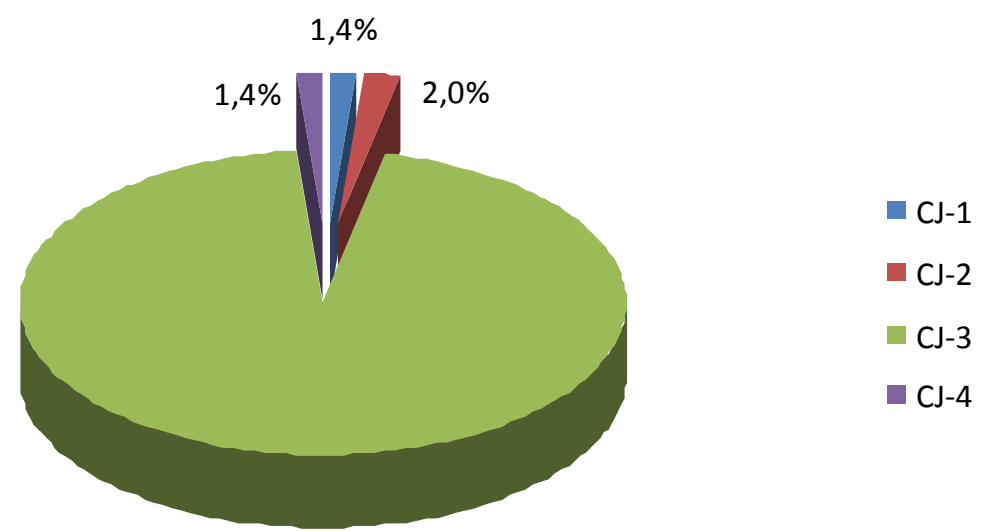

$95,3 \%$

Gráfico 7 - Tipo de Cargos Comissionados dos Sujeitos da Pesquisa 
Os dados do Gráfico 7 revelam que $93,4 \%$ dos participantes da pesquisa são ocupantes de Cargo Comissionado CJ-3. Esse resultado se justifica pelo fato de que, no STJ, o código CJ-3 engloba a maior parte dos Cargos Comissionados dos Gabinetes de Ministro e da Presidência.

\section{I) Tempo de Cargo Comissionado}

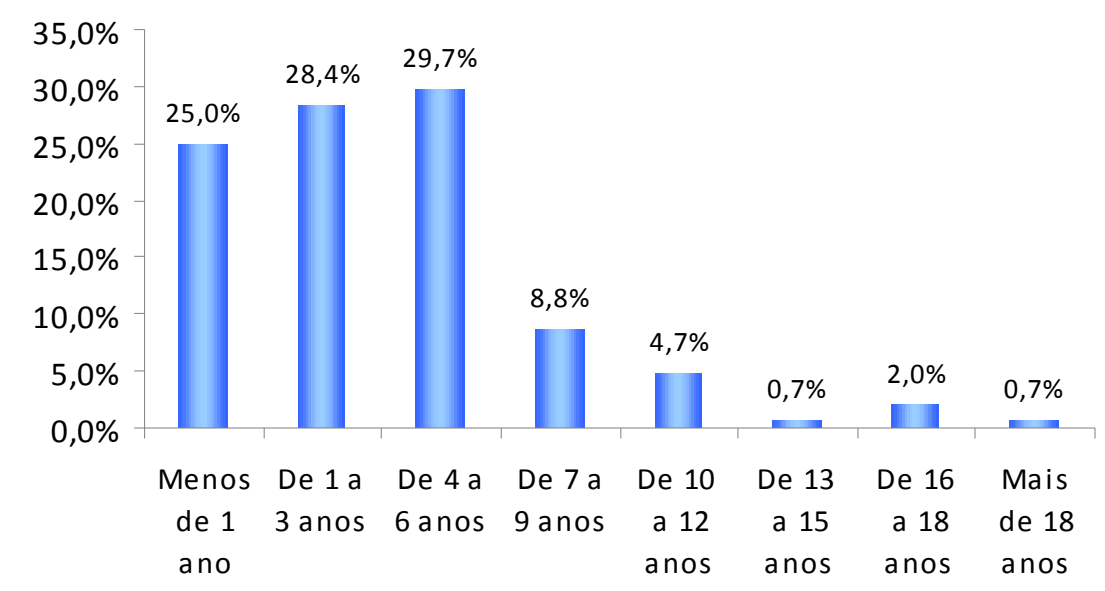

Gráfico 8 - Tempo de Cargo Comissionado dos Sujeitos da Pesquisa

Observa-se no Gráfico 8 que, com relação ao tempo de cargo comissionado, 29,1\% dos respondentes já estão ocupando cargo comissionado por um período de 4 a 6 anos. Vale ressaltar que os maiores percentuais estão nas faixas "menos de 1 ano", " de 1 a 3 anos" e de 4 a 6 anos". O menor percentual registrado foi de $0,7 \%$ que corresponde ao período de 13 a 15 anos. Esse resultado retrata a realidade dos cargos comissionados, marcada pela alta rotatividade dos seus ocupantes.

\subsection{Instrumento}

A pesquisa qualitativa foi realizada por meio de entrevistas individuais semiestruturadas (Apêndice A), enquanto que a pesquisa qualitativa utilizou o instrumento de O’Malley (1999), desenvolvido para investigar a percepção dos trabalhadores sobre a eficácia e as vantagens dos cursos a distância. O instrumento (Anexo A) é composto por 18 itens para serem respondidos em uma escala tipo "Lickert", de cinco pontos, variando de "discordo 
totalmente da afirmativa" a "concordo totalmente com a afirmativa". Os itens estão agrupados em duas dimensões - eficácia e vantagens dos cursos a distância.

Além dos itens que compunham o instrumento original de O'Malley, foram acrescidas ao questionário de pesquisa mais nove questões com o objetivo de identificar o perfil demográfico dos respondentes. Essas questões envolviam as seguintes variáveis: sexo; faixa etária; estado civil; escolaridade; lotação; tempo de exercício no Tribunal; tipo de vínculo com a Organização; tipo de cargo comissionado e tempo de cargo comissionado.

\subsection{Procedimentos de Coleta de Dados}

\subsubsection{Pesquisa Qualitativa}

As entrevistas foram realizadas no local do trabalho, em horário previamente combinado, com duração entre vinte e trinta minutos e gravadas, com expressa autorização dos entrevistados. Após finalização, todas as entrevistas foram degravadas e submetidas aos entrevistados para eventuais correções.

\subsubsection{Pesquisa Quantitativa}

Os questionários foram impressos e entregues pessoalmente pela própria pesquisadora, a um responsável em cada uma das 35 unidades do STJ que participaram da pesquisa. Houve a orientação de que seria preservado o anonimato dos respondentes. Posteriormente, dentro do prazo de uma semana, foi feita ligação para os responsáveis em cada unidade, indagando sobre a possibilidade do recolhimento dos questionários preenchidos.

\subsection{Procedimentos de Análise dos Dados}

Os dados da pesquisa qualitativa foram analisados por meio da técnica de "análise de conteúdo". Na pesquisa quantitativa utilizou-se o Statistical Package for Social Sciences (SPSS). 


\section{CAPÍTULO 3 - APRESENTAÇÃO E DISCUSSÃO DOS RESULTADOS}

O presente Capítulo apresenta e discute os resultados encontrados na pesquisa empírica conduzida para responder à seguinte questão: "É viável a implantação de um modelo de Universidade Corporativa no Poder Judiciário"? O trabalho teve por objetivo geral “investigar como estão sendo realizadas as atividades de treinamento e desenvolvimento no Superior Tribunal de Justiça (STJ), verificando sua adequação às necessidades de aprendizagem das organizações no século XXI”. Os seguintes objetivos específicos foram delineados:

- Revisar a literatura da área de treinamento e desenvolvimento de pessoal, com ênfase nos novos modelos de educação corporativa e universidade corporativa.

- Verificar se os servidores e gestores perceberam mudanças em relação às ações de treinamento, desenvolvimento e educação com a implantação do modelo de Educação Corporativa no STJ.

- Identificar a percepção dos servidores do STJ com relação ao uso da Educação a Distância como modalidade de ensino-aprendizagem.

- Verificar se o modelo de Educação Corporativa do Superior Tribunal de Justiça atende às demandas de aprendizagem do Órgão ou se deveria evoluir para um modelo de Universidade Corporativa.

Revisar a literatura da área de treinamento e desenvolvimento de pessoal, com ênfase nos novos modelos de educação corporativa e universidade corporativa foi o primeiro objetivo específico do trabalho. Esse objetivo foi atendido no Capítulo 1 da Monografia. Os resultados relacionados aos demais objetivos serão apresentados e discutidos a seguir.

\subsection{A Educação Corporativa no STJ na Perspectiva da Pesquisa Qualitativa}

Conforme mencionado na parte introdutória deste trabalho, desde 2005, o STJ começou a envidar esforços para reformular sua área de desenvolvimento de pessoas, buscando adequá-la as tendências vigentes nas organizações do século XXI que apontam para um modelo de Educação Corporativa. 
Assim, em fevereiro de 2007 foi instituída a Educação Corporativa STJ, inclusive com uma proposta de criação da Universidade Corporativa do Superior Tribunal de Justiça em 2008. A criação da Universidade Corporativa não chegou a se concretizar, em razão das mudanças de gestão ocorridas no Tribunal, mas várias ações do projeto Educação Corporativa STJ foram implementadas. Entre elas, destaca-se a elaboração da Matriz de Aprendizagem da Educação Corporativa, cujos principais pontos são:

\begin{tabular}{|c|c|c|c|c|}
\hline \multirow{2}{*}{ Vertentes } & \multirow{2}{*}{$\begin{array}{c}\text { Cidadania } \\
\text { Organizacional }\end{array}$} & \multirow{2}{*}{ Estratégica } & \multicolumn{2}{|r|}{ Funcional } \\
\hline & & & Gerencial & Técnico \\
\hline$\underset{8}{8}$ & $\begin{array}{l}\text { Valores } \\
\text { Institucionais. }\end{array}$ & $\begin{array}{l}\text { Competências } \\
\text { organizacionais voltadas } \\
\text { para os objetivos } \\
\text { estratégicos do STJ. }\end{array}$ & $\begin{array}{l}\text { Competências } \\
\text { humanas conforme } \\
\text { trajetória } \\
\text { profissional. }\end{array}$ & $\begin{array}{l}\text { Qualificação técnica } \\
\text { exigida conforme a área de } \\
\text { atuação. }\end{array}$ \\
\hline 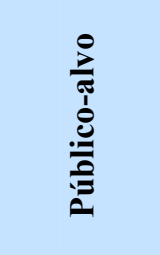 & $\begin{array}{l}\text { Todos os servidores } \\
\text { do Tribunal. }\end{array}$ & $\begin{array}{l}\text { Todos os servidores ou } \\
\text { áreas específicas do } \\
\text { Tribunal, estabelecidas a } \\
\text { partir das estratégias do } \\
\text { STJ. }\end{array}$ & $\begin{array}{l}\text { Servidores que } \\
\text { ocupam função } \\
\text { comissionada ou } \\
\text { cargo em comissão } \\
\text { de natureza } \\
\text { gerencial. }\end{array}$ & $\begin{array}{l}\text { Servidores conforme a área } \\
\text { de atuação. }\end{array}$ \\
\hline 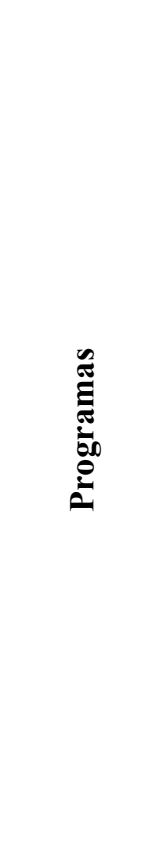 & $\begin{array}{l}\text { I - Programa STJ - } \\
\text { Um Referencial de } \\
\text { Excelência } \\
\text { II - Programa } \\
\text { Praticando Valores } \\
\text { III - Programa } \\
\text { Sintonia } \\
\text { Organizacional } \\
\text { IV - Programa } \\
\text { Inova Ação } \\
\text { V - Programa } \\
\text { Expandindo } \\
\text { Fronteiras de } \\
\text { Aprendizagem }\end{array}$ & $\begin{array}{l}\text { I - Programa Agilizando } \\
\text { os Caminhos Processuais } \\
\text { II - Programa Análise } \\
\text { Processual e Efetividade } \\
\text { Jurídica } \\
\text { III - Programa Integrando } \\
\text { o Sistema STJ } \\
\text { IV - Programa Bem } \\
\text { Servir, Bem Atender } \\
\text { V - Programa Melhoria } \\
\text { Tecnológica }\end{array}$ & $\begin{array}{l}\text { I - Programa } \\
\text { Planejando e } \\
\text { Gerindo o Alto } \\
\text { Desempenho } \\
\text { II - Programa } \\
\text { Conduzindo } \\
\text { Melhorias } \\
\text { III - Programa } \\
\text { Mobilizando } \\
\text { Pessoas }\end{array}$ & $\begin{array}{l}\text { SECRETARIA DE } \\
\text { GESTÃO DE PESSOAS } \\
\text { (SGP) } \\
\text { I - Programa Comunicação } \\
\text { para Resultados } \\
\text { II - Programa Formação de } \\
\text { Analistas de Desempenho e } \\
\text { Designers de Instrução } \\
\text { III - Programa Otimizando } \\
\text { o Uso da Tecnologia } \\
\text { IV - Programa Formação } \\
\text { de Analistas de Legislação } \\
\text { para a Cidadania } \\
\text { V - Programa de } \\
\text { Atualização Complementar } \\
\text { ára a área de Gestão de } \\
\text { Pessoas } \\
\text { VI - Programa Construindo } \\
\text { Relações Produtivas entre } \\
\text { Gestores, colaboradores e } \\
\text { Parceiros }\end{array}$ \\
\hline
\end{tabular}

Quadro 3 - Matriz de Aprendizagem do Superior Tribunal de Justiça

Entretanto, também conforme foi mencionado anteriormente, a literatura é enfática ao afirmar que a adoção de novas estratégias para treinar e desenvolver empregados implica importantes mudanças no ambiente organizacional. Dentre vários outros fatores, há necessidade de um maior envolvimento dos gestores e servidores da organização para que essas mudanças realmente aconteçam. 
Esta seção apresenta os resultados das entrevistas feitas com três grupos de pessoas que trabalham no STJ: a) gestores estratégicos; b) servidores da área de desenvolvimento de pessoas e c) servidores que participaram de ações educacionais oferecidas pelo STJ.

O objetivo dessas entrevistas foi verificar se os servidores e gestores do STJ perceberam mudanças em relação às ações de treinamento, desenvolvimento e educação com a implantação do modelo de Educação Corporativa. A análise do discurso dos entrevistados permitiu a separação dos dados em três categorias-sínteses que receberam as seguintes denominações:

- Educação Corporativa e Mudança Organizacional no STJ;

- Otimização da Educação Corporativa no STJ;

- Educação a Distância no STJ.

Assim, a partir da identificação dessas categorias foram construídos três quadros para cada um dos três grupos de entrevistados. A Figura 2 mostra essa distribuição:

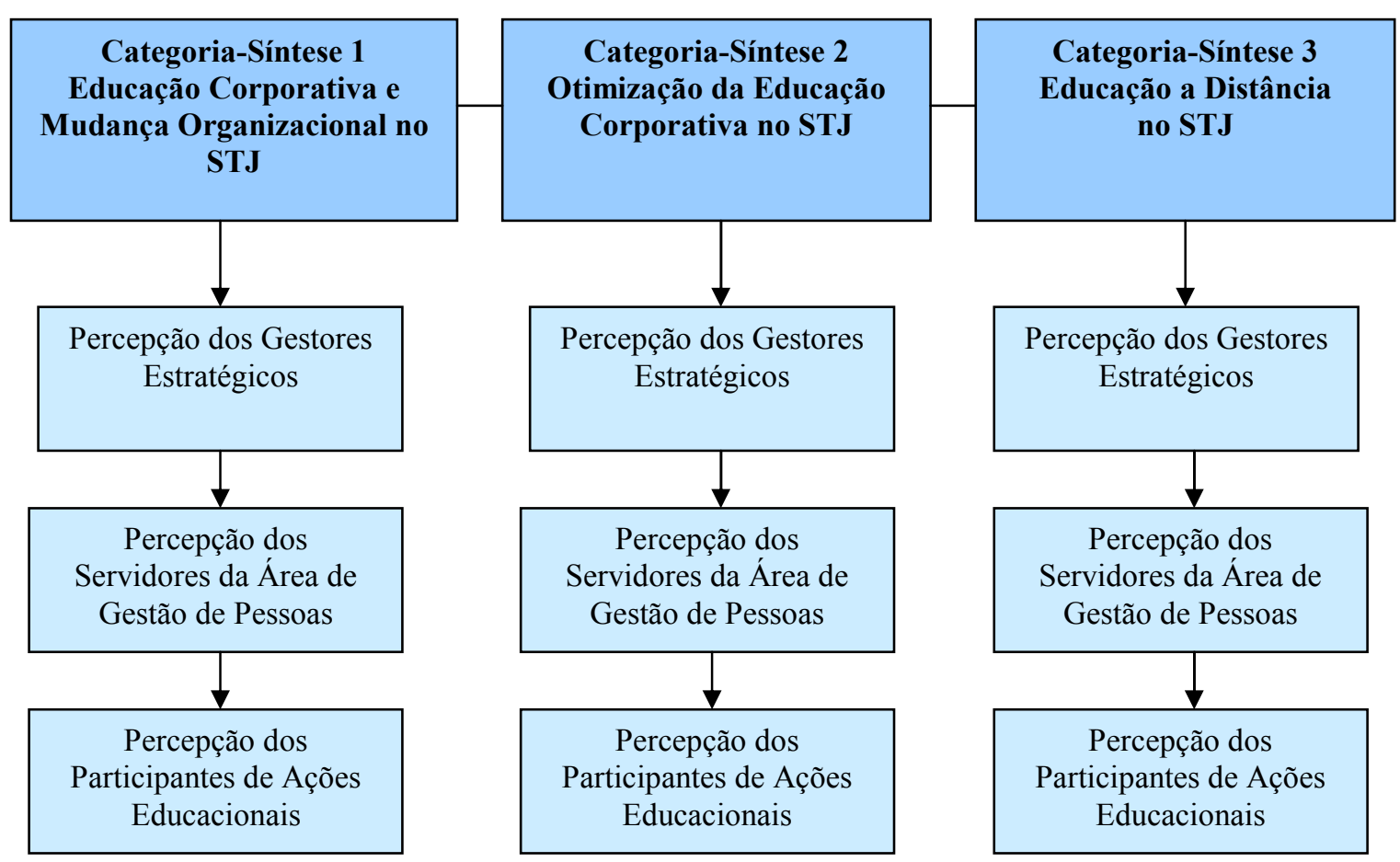

Figura 2 - Distribuição das Categorias-Sínteses por Grupos de Entrevistados 
As subseções seguintes apresentam os resultados da análise do discurso de cada grupo de entrevistados, organizados por cada uma das três categorias-sínteses encontradas.

\subsubsection{Educação Corporativa e Mudança Organizacional}

Esta seção mostra qual a percepção dos entrevistados sobre as mudanças ocorridas no STJ em relação às ações de treinamento, desenvolvimento e educação decorrentes da implantação da Educação Corporativa. Os Quadros 4, 5 e 6, sintetizam esse resultado:

\subsubsection{Grupo dos Gestores Estratégicos}

\section{Percepção dos Gestores Estratégicos}

Categoria Síntese 1: Educação Corporativa e Mudança Organizacional

Definição: Percebem-se muitas mudanças com a implantação da Educação Corporativa no STJ. Identifica-se a necessidade de ampliação do público-alvo, incluindo-se clientes e fornecedores, além da busca por metodologias alternativas de aprendizagem e incentivo à participação dos servidores.

\section{Exemplos de Verbalizações:}

"[...] pela primeira vez, com a Educação Corporativa, nós começamos a pensar, seriamente, na inclusão dos nossos clientes e fornecedores como pessoas que deveriam ser alcançados pelas ações educacionais".

"[...] eu vejo a mudança na questão da metodologia, na forma como os treinamentos deveriam ser desenvolvidos, nós passamos ao olhar para a educação como um processo que deveria ocorrer mito mais no local de trabalho, muito mais com metodologias alternativas".

“Eu passei a observar uma transformação, um pouco antes de 2007, mas 2007 foi quando mais se acentuou”.

“[...] o Tribunal passou a dar um tratamento mais inteligente aos treinamentos, incentivando, também, as pessoas a treinarem”.

“[...] foi um movimento muito inteligente. Agora, tem muitos desafios ainda”.

Quadro 4 - Educação Corporativa e Mudança Organizacional na Percepção dos Gestores Estratégicos 


\title{
3.1.1.2 Grupo dos Servidores da Área de Desenvolvimento de Pessoas
}

\author{
Percepção dos Servidores da Área de Desenvolvimento de Pessoas \\ Categoria Síntese 1: Educação Corporativa e Mudança Organizacional \\ Definição: A Educação Corporativa permite o planejamento das ações educacionais direcionando seu foco \\ para o negócio da instituição e maior aproximação com o cliente. \\ Exemplos de Verbalizações: \\ “Antes da Educação Corporativa nós tínhamos ações pulverizadas e depois, com a sua implantação, as ações \\ de desenvolvimento passaram a ser mais focadas no negócio da instituição”. \\ “[...] com a Educação Corporativa a gente dá mais ênfase ao planejamento dos eventos, de forma que cada \\ evento seja feito sob medida para a necessidade daquela unidade." \\ "[...] quando a gente faz esses eventos sob medida, para eles, junto com eles, definindo todo o planejamento \\ do evento: programa, instrutor, metodologia, essas pessoas se interessam mais pela capacitação e participam \\ mais. Inclusive, porque muitas vezes a ação fica tão focada que não demanda uma carga horária tão extensa, \\ o que facilita a participação das pessoas". \\ "[...] eu noto que houve uma mudança, sim, na atitude das pessoas no sentido de tentar uma aproximação \\ maior com o cliente, na hora de planejar as ações educacionais. ”.
}

Quadro 5 - Educação Corporativa e Mudança Organizacional na Percepção dos Servidores da Área de Desenvolvimento de Pessoas

\subsubsection{Grupo dos Servidores Participantes de Ações Educacionais}

Categoria Síntese 1: Educação Corporativa e Mudança Organizacional

Definição: Percebem-se mudanças com a implantação da Educação Corporativa no STJ, tais como, atendimento a demandas específicas da área fim do Tribunal, além de maior publicidade das ações e definição de público-alvo.

\section{Exemplos de Verbalizações:}

"Houve muitas mudanças, principalmente na questão de atender, especificamente a demanda da parte fim do Tribunal”.

"[...] teve uma publicidade maior, a partir do momento que começou a divulgar mais na intranet, porque muitas vezes vinha por e-mail e aí tinha gente que não recebia, quando lia o e-mail e ia fazer a inscrição já não tinha mais vaga".

“[...] a definição do público alvo, eu acho que é um das coisas fundamentais na Educação Corporativa”.

"[...] eu acho que o primeiro grande passo foi ter chamado representantes dos Gabinetes de Ministro para uma reunião, porque vocês ouviram as nossas carências e os nossos objetivos, o que a gente estava precisando. Acho que aquela reunião foi o grande diferencial para tudo, porque até então, eram só locados os cursos e a impressão que a gente tinha é que quem estava escolhendo o curso não tinha noção do trabalho que era desenvolvido nos Gabinetes de Ministro".

"Também foi uma oportunidade de conhecer os outros assessores da mesma seção que a gente trabalhava".

Quadro 6 - Educação Corporativa e Mudança Organizacional na Percepção dos Servidores Participantes de Ações Educacionais 
Os Quadros 4, 5 e 6 demonstram que há uma concordância no discurso dos entrevistados, no sentido de que a implantação da Educação Corporativa no STJ provocou mudanças nas ações educacionais ofertadas pela área de desenvolvimento de pessoas. De acordo com relatos, os eventos são planejados com a parceria de representantes do públicoalvo, possibilitando ações mais direcionadas para as necessidades do cliente, sem esquecer o negócio da Instituição.

Além disso, a forma de dar publicidade aos eventos também contribuiu para que a mudança fosse percebida. Capacitar clientes e fornecedores tornou-se uma necessidade. Diferentemente do que se pensava há poucos anos, hoje há uma preocupação em buscar alternativas para estender as ações educacionais para toda a cadeira de valor, sem que isso signifique a utilização de verba pública.

Assim, constata-se, a partir do discurso dos entrevistados, que são muitas as mudanças percebidas pelos três grupos no que tange aos eventos de capacitação após a implantação da Educação Corporativa no Tribunal.

\subsubsection{Otimização da Educação Corporativa}

Nesta seção são apresentadas sugestões dos entrevistados para a melhoria das ações de treinamento, desenvolvimento e educação, dentro do novo modelo de Educação Corporativa

adotado pelo STJ. Os Quadros 7, 8 e 9, apresentados a seguir, sintetizam os resultados encontrados para cada um dos três grupos de entrevistados. 


\subsubsection{Grupo dos Gestores Estratégicos}

\begin{tabular}{l} 
Percepção dos Gestores Estratégicos \\
\hline Categoria Síntese 2: Otimização da Educação Corporativa \\
Definição: Há necessidade de se mapear os treinamentos técnicos funcionais e investir no desenvolvimento \\
das Vertentes da Cidadania Organizacional e Estratégica.
\end{tabular}

\section{Exemplos de Verbalizações:}

“[...] eu vejo que é preciso definir, de uma maneira bem objetiva, os treinamentos técnicos funcionais, porque a tendo isso definido, como diz a Cristina D'Arce, não vai nunca ficar "caindo treinamento na nossa cabeça". Então, se tiver isso definido, a gente pode se dedicar mais, e ter mais tempo para poder implantar a vertente da Cidadania Organizacional e Estratégica, porque elas, realmente, é que fazem o diferencial da Educação Corporativa.".

“[...] é preciso trabalhar junto às chefias, aos responsáveis pelas diversas áreas os pontos de carência que eles têm. Isso tem que ser renovado sempre”.

"[...] é preciso intensificar a divulgação para as pessoas, para os servidores das oportunidades de treinamento, de conhecimento, de participação na Educação Corporativa”.

"Então, eu faria essa sugestão para o Tribunal: para, todos os servidores saberem, de uma maneira fácil, qual o treinamento que eles podem fazer e até treinamentos fora do momento crucial aqui, em épocas que, digamos assim, o serviço seja menos intenso".

Quadro 7 - Otimização da Educação Corporativa na Percepção dos Gestores Estratégicos

\subsubsection{Grupo dos Servidores da Área de Desenvolvimento de Pessoas}

\begin{tabular}{l} 
Percepção dos Servidores da Área de Desenvolvimento de Pessoas \\
\hline Categoria Síntese 2: Otimização da Educação Corporativa \\
\hline Definição: Verifica-se a necessidade de se envolver mais os gestores estratégicos no desenho das ações \\
educacionais. É importante, ainda, adequar as ações de desenvolvimento e educação ao planejamento \\
estratégico da Instituição e investir na capacitação dos servidores da área de desenvolvimento de pessoas.
\end{tabular}

\section{Exemplos de Verbalizações:}

"Acho que precisaria reforçar essas duas coisas, atuar mais com os gestores estratégicos e nas ações de metodologias alternativas de aprendizagem”.

"Eu acho que tinha que voltar mais para o planejamento estratégico".

"Fazer um planejamento mais adequado à realidade do tribunal, que não ficasse só em rotinas, um planejamento com visão de futuro e que a área de $T \& D$ fosse chamada à convergir todas as ações para esse planejamento"

“É preciso investir muito nas pessoas que estão na área de Desenvolvimento de Pessoas”.

Quadro 8 - Otimização da Educação Corporativa na Percepção dos Servidores da Área de Desenvolvimento de Pessoas 


\subsubsection{Grupo dos Servidores Participantes de Ações Educacionais}

\begin{tabular}{l} 
Percepção dos Servidores Participantes de Ações Educacionais \\
\hline Categoria Síntese 3: Otimizac̃a da Educação Corporativa \\
\hline Definição: Trabalhar profundamente os conhecimentos básicos. \\
Exemplos de Verbalizações: \\
“[...] para a Educação Corporativa eu acho que a gente tem que trabalhar mais aqueles conhecimentos \\
básicos, mas de forma profunda para a gente poder ter ferramenta de desenvolver um raciocínio para chegar \\
à resposta de uma questão que hoje é controvertida”. \\
“Eu acho que o nosso Tribunal é muito bom. A gente conversa com outros servidores de outros tribunais, \\
primeira instância, segunda instância, a gente conta como são feitos os treinamentos e todo mundo elogia, que \\
não tem nada parecido. Então, eu acho que, assim, como está, está muito bom. Não sei como poderia \\
melhorar”.
\end{tabular}

Quadro 9 - Otimização da Educação Corporativa na Percepção dos Servidores Participantes de Ações Educacionais

As sugestões de melhorias apresentadas pelos entrevistados diferem entre os três grupos e até entre os participantes de um mesmo grupo. Na visão dos Gestores Estratégicos, é preciso investir no desenho da matriz funcional/técnica como forma de antever as demandas das unidades. Sensibilizar os gerentes para a importância de promover a capacitação e atualização do corpo funcional sob sua responsabilidade ainda é prioritária. É imprescindível, também, facilitar o acesso do servidor às informações sobre as oportunidades de capacitação.

A necessidade de convergência dos eventos de capacitação, desenhados em parceria com os gestores estratégicos, às metas definidas no Plano de Ação do Tribunal são constatadas na fala do grupo de servidores da área de desenvolvimento de pessoas. Outra sugestão do grupo é preparar os servidores da área para melhor desempenhar suas atividades.

O grupo formado por servidores participantes de ações educacionais dá ênfase no conteúdo a ser trabalhado na capacitação do corpo funcional.

A partir dessas reflexões, é possível extrair diversas sugestões que podem ser aplicadas à Educação Corporativa STJ, como forma de otimizar o resultado do investimento em ações de treinamento, desenvolvimento e educação. 


\subsubsection{Educação a Distância no STJ}

Observa-se, conforme relatos da literatura, que a Educação a Distância tem sido cada vez mais utilizada como alternativa para a formação e capacitação de pessoal nas organizações. O Superior Tribunal de Justiça, a exemplo de outras instituições públicas brasileiras, também tem buscado seguir essa tendência. Esta seção apresenta o resultado da percepção dos grupos entrevistados sobre o uso da Educação a Distância no STJ para a realização de ações educacionais.

\subsubsection{Grupo dos Gestores Estratégicos}

Categoria Síntese 3: Educação a Distância no STJ

Definição: O uso da Educação a Distância parece ser fundamental para o STJ, principalmente nos Gabinetes de Ministro, onde a demanda por novos conhecimentos é grande, mas o volume de trabalho muitas vezes dificulta que o servidor se ausente do local de trabalho para participar de ações educacionais.

\section{Exemplos de Verbalizações:}

"[...] a gente percebe que é uma necessidade aqui, principalmente nos gabinetes dos ministros, onde as pessoas estão abarrotadas de trabalho e, ao mesmo tempo, são demandadas por novos conhecimentos $e$ habilidades, seja pela atualização legislativa seja pelo avanço da tecnologia, seja pela necessidade de aperfeiçoar processo de trabalho e de gestão".

"[...] a educação a distância é fundamental para poder possibilitar às pessoas que trabalham em Gabinete e que não conseguem ser liberadas para participar de treinamento, e, além disso, a gente conseguir, realmente, universalizar essas ações educacionais que todos têm que passar por elas, que é o caso da Cidadania Organizacional e da Estratégia”.

"[...] ter uma alternativa para esses treinamentos que são à distância, poder fazer em casa, poder utilizar algum local aqui do Tribunal”.

Quadro 10 - Aceitação da Educação a Distância na percepção dos Gestores Estratégicos 


\title{
3.1.3.2 Grupo dos Servidores da Área de Desenvolvimento de Pessoas
}

\begin{tabular}{|l|}
\hline \multicolumn{2}{|c|}{ Percepção dos Servidores da Área de Desenvolvimento de Pessoas } \\
\hline Categoria Síntese 3: Educação a Distância no STJ \\
\hline $\begin{array}{l}\text { Definição: Metodologia indicada, principalmente, para gestores e assessores de Ministros. Necessidade de } \\
\text { investir na Educação a Distância. Boa aceitabilidade nas ações já desenvolvidas nessa metodologia. }\end{array}$
\end{tabular}

\section{Exemplos de Verbalizações:}

"É indicada essa metodologia no Tribunal, principalmente para os gestores e para os assessores nos gabinetes de ministros que têm dificuldade de participação nos eventos presenciais, porque ficam muito envolvidos com o trabalho".

“Poucas ações foram feitas nessa modalidade a distância. Precisamos reforçar mais isso”.

"Nas experiências que nós tivemos houve uma boa aceitabilidade”.

“Acho que esse também é um ponto fraco que precisa ser melhorado, porque a maioria das ações que promovemos, ainda são presenciais. E como a demanda é muito grande, tem uma defasagem muito grande de conhecimento no Tribunal”.

"Tem muita coisa que dá para se fazer sem grandes investimentos em tecnologia e que vai permitir que alcancemos um número maior de pessoas".

Quadro 11 - Aceitação da Educação a Distância na Percepção dos Servidores da Área de Desenvolvimento de Pessoas

\subsubsection{Grupo dos Servidores Participantes de Ações Educacionais}

\author{
Definição: Desconhecimento sobre o funcionamento da modalidade a distância. As pessoas não sabem como é \\ feita a avaliação nesse tipo de modalidade de ensino-aprendizagem, bem como desconhecem a eficácia dos \\ diferentes tipos de mídias que a EaD pode utilizar.
}

\section{Exemplos de Verbalizações:}

"Como vai fazer a avaliação? Fica muito subjetiva a questão. Acho que tem que desenvolver uma metodologia mais adequada para o serviço público”.

"Talvez pudesse pensar em curso a distância nesse sentido, de que o instrutor dê essa aula lá e a gente assista aqui, inclusive com possibilidades de fazer as perguntas por e-mail e ele responder as perguntas aqui, se a gente estiver fazendo em tempo real".

"Eu nunca fiz, não sei dizer, não tenho experiência”.

Quadro 12 - Aceitação da Educação a Distância na Percepção dos Servidores Participantes de Ações Educacionais 
Pela análise dos Quadros 10 e 11 observa-se que os grupos de Gestores Estratégicos e Servidores da Área de Desenvolvimento de Pessoas consideram a Educação a Distância como metodologia importante, principalmente para gestores e assessores de Ministros, que têm dificuldades para se ausentar da unidade de trabalho. Eles acreditam que é necessário investir nessa metodologia como forma de aumentar a acessibilidade aos treinamentos.

Entretanto, essa sintonia entre os gestores estratégicos e os servidores que trabalham na área de desenvolvimento de pessoas do STJ não é compartilhada pelos participantes do terceiro grupo de entrevistados - Servidores Participantes de Ações Educacionais.

Uma análise do discurso desses entrevistados, sintetizado no Quadro 12, permite identificar um total desconhecimento sobre as vantagens e eficácia da Educação a Distância. Observa-se, na fala desse grupo de entrevistados, que alguns manifestaram dúvidas sobre a possibilidade de se avaliar os alunos que estudam a distância. Outros consideram que a utilização da Educação a Distância no STJ somente seria possível caso a mídia utilizada fosse a videoconferência, onde professor e alunos poderiam interagir ao mesmo tempo, reproduzindo o formato da sala de aula presencial.

O discurso que emergiu desse grupo de entrevistados sinaliza que, caso o STJ pretenda investir mais na Educação a Distância para formar e capacitar os seus servidores, é prudente que desenvolva, antes, uma forte campanha de esclarecimento sobre essa modalidade de ensino-aprendizagem. O desconhecimento por parte dos servidores sobre as vantagens e a eficácia da Educação a Distância pode retardar ou prejudicar a implantação plena dessa modalidade no STJ. Como a Educação a Distância é um dos principais eixos em que se apóia o modelo de Educação Corporativa, faz-se importante e imprescindível essa campanha de sensibilização dos servidores.

\subsection{A Educação a Distância no STJ na Perspectiva da Pesquisa Quantitativa}

Conforme mencionado no subitem 2.4 do Capítulo 2, na pesquisa quantitativa foi utilizado um instrumento de O'Malley (1999), contendo 16 itens que avaliavam a percepção dos servidores do STJ acerca da eficácia e das vantagens de cursos feitos a distância. Esse instrumento foi utilizado para se alcançar o terceiro objetivo estabelecido na pesquisa identificar a percepção dos servidores do STJ com relação ao uso da Educação a Distância como modalidade de ensino-aprendizagem. 
O instrumento de O'Malley (1999) agrupou os 16 itens em duas dimensões a que o autor denominou de: a) eficácia de cursos a distância e b) vantagens dos cursos a distância. A Tabela 2 apresenta a média e o desvio padrão encontrado para cada uma das duas dimensões:

Tabela 2 - Média e Desvio Padrão das Dimensões do Instrumento

\begin{tabular}{|l|c|c|}
\hline \multicolumn{1}{|c|}{ Dimensões } & Média & Desvio Padrão \\
\hline Eficácia & 2,67 & 0,93 \\
\hline Vantagens & 3,36 & 0,57 \\
\hline
\end{tabular}

Na primeira dimensão, que mensura a percepção dos servidores com relação à eficácia dos cursos a distância, observa-se que a média da respostas dos sujeitos foi 2,67, situando-se entre os pontos da escala "discordo um pouco da afirmativa" e "não concordo nem discordo da afirmativa”. Esse resultado sinaliza que, no Superior Tribunal de Justiça (STJ), os participantes da pesquisa não acreditam muito na eficácia dos cursos a distância. $O$ desvio padrão nessa primeira dimensão foi de 0,93 , indicando que houve pouca divergência entre os respondentes com relação às respostas dadas aos itens do instrumento que cobriam essa dimensão. O Quadro 3 apresenta exemplos de alguns dos itens que compõem a dimensão "Eficácia da EaD":

\begin{tabular}{|c|c|}
\hline Dimensão & Descrição do Item \\
\hline \multirow{3}{*}{ Eficácia da EaD } & $\begin{array}{l}\text { A maioria das pessoas acredita que um curso a } \\
\text { distância é mais efetivo do que um curso } \\
\text { presencial. }\end{array}$ \\
\hline & $\begin{array}{l}\text { Eu acredito que posso aprender a mesma } \\
\text { quantidade de conteúdo, tanto no curso a distância } \\
\text { como no curso presencial. }\end{array}$ \\
\hline & $\begin{array}{l}\text { Eu acredito que posso aprender mais por um } \\
\text { material on-line do que por uma aula expositiva. }\end{array}$ \\
\hline
\end{tabular}

Quadro 13 - Exemplos dos Itens da Dimensão "Eficácia da EaD”

A segunda dimensão mensura a percepção dos servidores com relação às vantagens oferecidas pelos cursos a distância. Nessa dimensão, a média das respostas foi de 3,36, 
situando-se entre os pontos da escala "não concordo nem discordo da afirmativa" e "concordo um pouco com a afirmativa". Esse resultado sinaliza que os servidores do STJ que participaram da pesquisa reconhecem, embora não totalmente, as vantagens oferecidas pelos cursos feitos na modalidade a distância. O baixo desvio padrão encontrado, 0,57, aponta uma alta concordância entre os respondentes da pesquisa com relação aos itens dessa segunda dimensão. O Quadro 14, apresentado a seguir, mostra exemplos dos itens que formam a dimensão "Vantagens da EaD":

\begin{tabular}{|c|l|}
\hline Dimensão & \multicolumn{1}{|c|}{ Descrição do Item } \\
\hline \multirow{2}{*}{$\begin{array}{c}\text { Vantagens da } \\
\text { EaD }\end{array}$} & $\begin{array}{l}\text { Eu me beneficiaria se houvesse mais cursos a } \\
\text { distância. }\end{array}$ \\
\cline { 2 - 2 } & Cursos a distância me economizariam tempo. \\
\cline { 2 - 2 } & $\begin{array}{l}\text { Eu conseguiria ter uma frequência melhor num } \\
\text { curso a distância do que tenho no presencial. }\end{array}$ \\
\hline
\end{tabular}

Os resultados apresentados nesta seção apontam um aspecto importante e que deve ser considerado pela área de desenvolvimento de pessoas do STJ. Na Instituição, observou-se que os servidores têm dúvidas com relação à eficácia da Educação a Distância, embora alguns cheguem a concordar com algumas vantagens que essa modalidade de ensino-aprendizagem pode oferecer.

Esse resultado sinaliza que, caso o STJ pretenda investir mais em cursos a distância, seria interessante que houvesse, antes, uma campanha de sensibilização. Essa campanha incluiria material explicativo sobre o que é Educação a Distância, quais as suas vantagens e o papel estratégico que ela vem assumindo nas últimas décadas, tanto na iniciativa pública como na iniciativa privada.

\subsection{A Educação Corporativa STJ e os dez componentes fundamentais do Projeto de uma Universidade Corporativa}

Esta seção faz uma análise dos componentes constantes da Figura 1, apresentada no Capítulo 1 deste trabalho, comparando os dez componentes fundamentais necessários para o sucesso de uma universidade corporativa, conforme citado na literatura, e a realidade do órgão estudado. 


\subsubsection{Sistema de Controle}

Meister (1999) argumenta que, além do envolvimento da alta cúpula da administração na criação de uma UC, é necessária a criação de um sistema de controle no qual estejam envolvidos outros gerentes com a finalidade de desenvolver uma visão compartilhada da UC.

Ainda segundo a autora, cabe ao sistema controlador identificar e priorizar as necessidades de aprendizagem atuais e futuras, vincular o treinamento às principais estratégias da empresa, assegurar projeto, desenvolvimento, apresentação e avaliação consistentes e oferecer orientação para o desenvolvimento de uma filosofia de aprendizagem.

A Educação Corporativa STJ, instituída em 2007, está estruturada em três vertentes: Cidadania Organizacional, Estratégica e Funcional. Cada uma possui programas que devem ser desenhados para propiciar o desenvolvimento das competências definidas no início do projeto. Até o presente momento já foram lançados alguns programas das vertentes "Estratégica" e "Cidadania Organizacional".

A elaboração das ações educacionais dos programas é definida por diversos gerentes da Organização, denominados gestores estratégicos. Esses gestores foram convidados a contribuir no projeto por possuírem experiência e visão sistêmica, entre outros fatores. A sua participação é de fundamental importância, pois além do sentimento de colaboração experimentado por cada um deles quando da realização de um evento do programa do qual fazem parte, passa ao restante da organização a idéia de comprometimento e importância. Além disso, por fazerem parte do corpo gerencial, sabe-se que o volume de trabalho e significativo e, mesmo assim, eles conseguem conciliar suas agendas de modo a participarem das reuniões de acompanhamento do programa do qual fazem parte.

Nesse sentido, conclui-se que a participação dos gestores estratégicos da Educação Corporativa STJ demonstra a existência de um sistema de controle, como previsto na literatura.

\subsubsection{Visão e Missão}

De acordo com Meister (1999), é ideal que toda UC tenha uma visão de futuro e a sugestão é que sua construção seja de responsabilidade de todo o órgão controlador. Ainda segundo a autora "O ideal é que tudo seja produto de um esforço conjunto" (MEISTER, 1999, p. 70). 
Nos documentos consultados para a elaboração desse trabalho não foram encontrados indícios da existência de visão própria da Educação Corporativa. Os fatos indicam que se utiliza a visão e missão do Órgão como orientadores das suas ações.

\subsubsection{Fontes de Receita}

$\mathrm{O}$ alcance das operações de uma universidade corporativa deve ser definido no início do projeto para que, a partir daí, possa ser previsto o orçamento necessário à execução das ações. De acordo com Meister (1999) a origem das verbas pode estar na alocação corporativa ou cobrança por serviços prestados às unidades de negócios e do licenciamento de treinamentos para clientes, fornecedores e organizações-chave dentro da cadeia de valor.

$\mathrm{Na}$ Instituição estudada, essa realidade é diferente, pois se trata de uma organização pública que, como tal, tem o seu orçamento anual assegurado por Lei. Do valor total desse orçamento consta uma rubrica específica para ações de capacitação, o que permite à unidade gestora dessa verba planejar, em conjunto com os gestores estratégicos, todos os eventos do ano.

Entretanto, há limites para o a utilização desse montante, tais como, não poder capacitar terceirizados, estagiários, clientes e fornecedores. Mesmo com essas restrições, os gestores estratégicos e os servidores da área de gestão de pessoas têm procurado alternativas para alcançar o público-alvo não beneficiado com as ações que demandam orçamento. Uma das propostas dos gestores é que eles mesmos possam atuar, sem ônus para os cofres públicos, como instrutores em ações dessa natureza.

Verifica-se, então, que os limites impostos pela legislação podem dificultar a atuação da universidade corporativa como sugere a literatura, no que diz respeito à captação de verbas. Esse fato, porém, não impede, conforme demonstrado, o surgimento de alternativas para que se aumente o escopo de atuação da universidade corporativa.

\subsubsection{Organização}

Criar uma organização não quer dizer que todo o treinamento deverá ficar a cargo de uma só supervisão, diz Meister (1999). A autora complementa que algumas ações podem ser centralizadas em razão de custo e eficiência, enquanto outras podem ser descentralizadas para que permaneçam perto dos clientes. A decisão sobre o que deve ser centralizado ou 
descentralizado deve ser feita mediante a utilização de critérios que permitam avaliar a relação custo-benefício.

No caso da organização estudada, todas as ações são centralizadas na unidade de desenvolvimento de pessoas, não havendo, atualmente, necessidade de descentralização, visto que o Órgão se concentra na Capital Federal, possuindo somente duas unidades externas.

\subsubsection{Partes Interessadas}

A amplitude do público-alvo é um dos aspectos que distingue uma universidade corporativa do departamento tradicional de T\&D, afirma Meister (1999). Uma vez definida a clientela, o próximo passo é identificar suas necessidades e enfocar aquelas que darão maior projeção à universidade corporativa. Meister (1999) afirma ser importante identificar objetivos, público-alvo, problema empresarial e lacuna entre competências atuais e futuras que serão imprescindíveis para garantir o sucesso da organização.

As ações oferecidas pela Educação Corporativa STJ estão, pouco a pouco, se aproximando do que sugere a literatura. Hoje, além da participação dos gestores no desenho dos eventos, há consulta ao público-alvo para definir desde o conteúdo até o instrutor, passando por carga-horária e desempenho esperado dos participantes após a ação de desenvolvimento. Essa forma de atuar parece estar surtindo melhores efeitos, de acordo com avaliações de reação de alguns treinamentos.

\subsubsection{Produtos e Serviços}

Depois de identificadas as competências da organização, o próximo passo é desenvolver um modelo de soluções de aprendizagem. Isso significa ir além dos cursos tradicionais. É buscar metodologias alternativas que favoreçam a aquisição de conhecimentos. Segundo a autora, o compartilhamento de melhores práticas é, acima de tudo, aprendizagem informal e voluntária que pode se espalhar pela organização propiciando a oportunidade de transferência de conhecimento.

Um bom exemplo dessa aprendizagem informal na organização estudada é o encontro realizado por um grupo de servidores que trabalham em um determinado ramo do Direito. Eles se reúnem periodicamente para trocar experiências e, assim, descobrir nova ótica para a solução de algum conflito existente. Conforme relatos de participantes, essas reuniões 
favorecem, além da oportunidade de ampliar seu leque de conhecimentos, a criação de uma network.

Mas vale lembrar, que cabe a universidade corporativa difundir essa prática de modo que outros grupos de trabalho possam, também, aplicá-la. Assim, verifica-se que nesse ponto a Organização já busca novas formas de promover o conhecimento.

\subsubsection{Parceiros de Aprendizagem}

De acordo com a autora, depois de definido o modelo de aprendizagem, a universidade corporativa deve selecionar seus parceiros, que podem ser instrutores, consultores e instituições de educação superior. Ela ressalta que em face da excelência na constante atualização da base de conhecimentos da universidade corporativa, há uma propensão de unir forças com os mais diferentes parceiros educacionais para integrar as metas de cada funcionário, o que é benéfico para todas as partes.

Apesar de contar com uma gama de instrutores e instituições educacionais cadastrados para a realização de eventos, o Órgão não tem, atualmente, parcerias firmadas, sejam por convênio ou contrato. É certo que futuramente essa necessidade deverá ser atendida.

\subsubsection{Tecnologia}

Atualmente é impossível pensar em pessoas sem pensar em tecnologia. Ela é utilizada nos bancos, escolas, hospitais, residências e organizações, atingindo quase todas as camadas da população. Quando a questão é educação, é imprescindível estar conectado às últimas tendências, como forma de garantir maior acessibilidade com menor custo. Assim, as organizações devem esboçar a estratégia tecnológica a ser utilizada pela universidade corporativa preferencialmente antes do início do projeto, conforme sugere Meister (I999).

$\mathrm{Na}$ organização estudada o avanço tecnológico é visível. Percebe-se, entretanto, que sua utilização como metodologia complementar de aprendizagem ainda é insignificante. São poucas as ações educacionais disponibilizadas no formato a distância, se comparada com outras metodologias. 


\subsubsection{Avaliação}

Criar um sistema de avaliação é outro ponto importante a ser considerado para o sucesso da universidade corporativa, afirma Meister (1999). Não basta ter dados sobre montante investido, horas de treinamento por colaborador por ano ou número de oportunidades de capacitação oferecidas pela instituição, visto que esses indicadores revelam apenas o investimento em treinamento. É ainda mais importante avaliar os resultados produzidos por essas ações, como forma de institucionalizar a universidade corporativa.

Vargas (2004) esclarece que, no mundo corporativo, em geral os cursos são avaliados usando-se os modelos clássicos consagrados na literatura de treinamento e desenvolvimento de pessoal. Entre os vários modelos existentes destacam-se os de Kirkpatrick (1976) e o de Hamblin (1978). No Brasil, esclarece a autora, também são usados os modelos de BorgesAndrade (1982) e o de Abbad (1999).

No STJ, observa-se que o modelo mais utilizado ainda é o de Kirkpatrick (1976), que engloba quatro níveis de avaliação:

- Reação (Nível 1) - Avalia como o servidor reage ao evento instrucional realizado. É uma medida de satisfação do cliente. Avalia aspectos instrucionais e administrativos.

- Aprendizagem (Nível 2) - Avalia mudança de atitude, melhoria do conhecimento e/ou aumento das habilidades.

- Comportamento no Cargo (Nível 3) - Avalia mudança do desempenho do servidor no cargo ocorrida em função da realização do evento instrucional.

- Resultados (Nível 4) - Avalia os benefícios obtidos pela organização em função da participação dos servidores em eventos instrucionais.

Segundo a literatura, o Nível 1 é uma das formas de avaliação mais utilizadas pelas organizações, em razão da facilidade de aplicação e tabulação dos dados. Entretanto, a literatura também é enfática no sentido de que os dados decorrentes desse tipo de avaliação podem ser considerados insuficientes para permitir a institucionalização do modelo de universidade corporativa.

No caso dos cursos a distância, por exemplo, é importante a aplicação do Nível 2 Avaliação de Aprendizagem - como forma de acompanhamento e controle da absorção do 
conteúdo ensinado. O Nível 3 - Comportamento no Cargo - é um tipo de avaliação que também tem sido utilizado pelas organizações, porém em menor escala. Por se tratar de um processo mais complexo e oneroso de avaliação, pois requer a auto-avaliação, avaliação dos pares e avaliação das chefias, normalmente é feito em cursos considerados mais estratégicos. O Nível 4 - Resultados - ainda segundo relatos da literatura é o menos utilizado pelas organizações, em razão da alta complexidade e investimentos necessários à sua execução de forma correta.

No STJ, conforme verificado em documentos da Instituição, atualmente se utiliza apenas o Nível 1 - Reação. Esse resultado aponta a necessidade do Órgão de implementar a aplicação de, pelo menos, mais dois níveis - "Aprendizagem" e "Comportamento no Cargo".

\subsubsection{Comunicação Constante}

Para garantir que os colaboradores assimilem o que vem a ser uma universidade corporativa é necessário investir na comunicação. Não adianta criar uma missão inspiradora para a universidade corporativa, reunir alguns gerentes para apresentá-la ou realizar “demonstrações práticas”, relata a autora. Essas comunicações podem aumentar o descrédito das pessoas em relação a essa forma de atuação.

A autora afirma, também, que o valor de uma universidade corporativa deve ser comunicado de modo efetivo, exigindo o envolvimento de muitos colaboradores que devem saber exatamente porque se decidiu investir nesse projeto. A comunicação deve levar em conta as perguntas básicas sobre uma universidade corporativa, tais como: o que é universidade corporativa, por que a aprendizagem é importante para a organização, dentre outras.

$\mathrm{Na}$ organização estudada há um grande investimento em comunicação sobre a educação corporativa. Para o seu lançamento foi distribuído folder informativo (Anexo D) e o material utilizado na divulgação e realização dos eventos é aperfeiçoado com certa freqüência. Mesmo com o envolvimento pessoal de todos que atuam na área de desenvolvimento de pessoas e dos gestores estratégicos, verifica-se que grande parte dos colaboradores ainda não percebe diferenças entre o modo tradicional de T\&D e a educação corporativa.

Conforme mencionado anteriormente, esta seção pretendeu fazer uma análise dos dez componentes fundamentais necessários para o sucesso de uma universidade corporativa, citados por Meister (1999), comparando-os com a realidade do STJ. A idéia era verificar até 
que ponto o modelo de Educação Corporativa STJ se aproxima do modelo de uma universidade corporativa. Depreende-se da análise feita, que dos dez componentes presentes no modelo de universidade corporativa visualizado por Meister (1999), apenas cinco estão presentes no modelo de Educação Corporativa STJ. Esses componentes são:

- Sistema de Controle

- Fontes de Receita

- Organização

- Partes Interessadas

- Produtos e Serviços 


\section{CONSIDERAÇÕES FINAIS}

O presente trabalho teve por objetivo investigar como estão sendo realizadas as atividades de treinamento e desenvolvimento no Superior Tribunal de Justiça (STJ), verificando sua adequação às necessidades de aprendizagem das organizações do século XXI.

A pesquisa identificou que, desde 2005, o STJ tem envidado esforços para adotar um novo modelo de atuação para a área de desenvolvimento de pessoas. Seguindo uma tendência atual das organizações, foi instituída, em 2007, a Educação Corporativa do Superior Tribunal de Justiça. No ano de 2008, houve uma proposta de criação da Universidade Corporativa do Superior Tribunal de Justiça (UNIJUS), mas o projeto ainda não foi implementado, em razão de mudanças de gestão ocorridas no Tribunal.

Utilizando duas abordagens de pesquisa - qualitativa e quantitativa - foi possível analisar o cenário atual das atividades de treinamento e desenvolvimento do STJ. Dessa análise podem ser destacados os seguintes pontos:

- A Educação Corporativa no STJ - Ficou evidenciada, nos três grupos de entrevistados, que é percebida uma mudança na forma como o STJ passou a conduzir as atividades de treinamento e desenvolvimento após a introdução do modelo de Educação Corporativa. A mudança realmente aconteceu e teve uma avaliação favorável por parte dos diferentes segmentos entrevistados - gestores estratégicos, servidores da área de gestão de pessoas e servidores que participam de ações educacionais disponibilizadas pelo Órgão.

- A Educação a Distância no STJ - Na pesquisa qualitativa feita com os três grupos de entrevistados ficou clara que há percepções diferentes com relação ao uso da Educação a Distância no STJ. Os gestores estratégicos e os servidores da área de gestão de pessoas demonstraram ter uma visão bastante favorável com relação a essa modalidade de ensino-aprendizagem. Entretanto, o terceiro grupo de entrevistados, formado por servidores que participam de ações educacionais, demonstrou ser pouco informado sobre o tema. Os resultados da pesquisa quantitativa, obtidos com a aplicação do instrumento desenvolvido por O'Malley (1999), reforçou esse dado, 
sinalizando que entre os respondentes há ainda pouca certeza com relação às vantagens e a eficácia da Educação a Distância.

- O Modelo de Universidade Corporativa - Dos dez componentes fundamentais necessários para o sucesso de uma universidade corporativa, citados por Meister (1999), cinco já estão presentes no modelo de Educação Corporativa do STJ. Esse é um dado importante, caso a Instituição resolva dar prosseguimento à implantação da Universidade Corporativa do Superior Tribunal de Justiça (UNIJUS).

O problema de pesquisa investigado neste trabalho - "É viável a implantação de um modelo de Universidade Corporativa no Poder Judiciário?" - nasceu da necessidade de repensar as ações de treinamento e desenvolvimento de pessoal no âmbito do Superior Tribunal de Justiça. Como resposta a essa questão os resultados encontrados na pesquisa permitem observar que em alguns pontos o STJ já evoluiu do T\&D tradicional para um modelo de educação corporativa. Entretanto, tomando-se por base os dez elementos citados por Meister (1999), há ainda alguns desafios a serem vencidos para tornar viável a implantação de uma universidade corporativa. Entre eles, destacam-se:

- Dar ênfase na construção da visão e missão da universidade corporativa.

- Selecionar parceiros de aprendizagem que possam efetivamente contribuir para a melhoria das ações ofertadas.

- Estimular o uso da tecnologia para tornar a aprendizagem mais acessível.

- Adotar níveis mais complexos de avaliação que se estendam além da reação dos participantes aos eventos instrucionais.

- Melhorar a comunicação como forma de propiciar maior credibilidade ao modelo adotado.

Além desses cinco elementos, é importante ressaltar outro importante resultado apontado pela pesquisa empírica - o desconhecimento, por parte de alguns servidores do STJ, das vantagens e da eficácia da Educação a Distância. Como essa modalidade de ensinoaprendizagem é um dos principais eixos que sustentam o modelo de universidade corporativa, torna-se prioritário que o STJ invista em uma campanha de sensibilização dos servidores para a importância do tema. A elaboração de cartilhas, a realização de palestras e 
mesmo a oferta de um pequeno curso auto-instrucional sobre Educação a Distância poderão ajudar no esclarecimento dos servidores.

Ainda que os resultados encontrados nesta pesquisa não possam ser generalizados, em virtude do reduzido número de participantes, espera-se que eles sirvam de incentivo na proposição de melhorias para a área de desenvolvimento de pessoas, bem como possibilitem a realização de estudos mais aprofundados sobre o tema. 


\section{REFERÊNCIAS}

ALPERSTEDT, C. Universidades corporativas: discussão e proposta de uma definição. In: ENCONTRO NACIONAL DA ASSOCIAÇÃO NACIONAL DOA PROGRAMAS DE PÓSGRADUAÇÃO E PESQUISA EM ADMINISTRAÇÃO, 24ㅇ․ 2000, Florianópolis, ENANPAD, Resumo dos Trabalhos: Rio de Janeiro. Metrópole

BARDIN, L. Análise de conteúdo. Portugal: Edições 70, 2008.

BRANDÃO, G. R. Gestão de pessoas es universidades corporativas: dois lados da mesma moeda? Revista de Administração de Empresas. São Paulo, v.46. n 2, p. 22-33, abr./jun. 2006.

BRASIL. Constituição Federal de 1998. Obra atualizada em 2008 Disponível em: $<$ http://www.planalto.gov.br>. Acesso em: 15 ago. 2008.

DENGO, N.; Universidades corporativas: modismo ou inovação?. In: ENCONTRO NACIONAL DA ASSOCIAÇÃO NACIONAL DOA PROGRAMAS DE PÓSGRADUAÇÃO E PESQUISA EM ADMINISTRAÇÃO, 26², 2002, Salvador. ENANPAD. Resumo dos Trabalhos.Rio de Janeiro: Metrópole, 2002.

ÉBOLI, M. Educação corporativa no Brasil: mitos e verdades. São Paulo: Editora Gente, 2004.

MARCONDES, R. C.; PAIVA, J. A: Afinal, a universidade corporativa é uma T\&D revisitada? In: ENCONTRO NACIONAL DA ASSOCIAÇÃO NACIONAL DOA PROGRAMAS DE PÓS-GRADUAÇÃO E PESQUISA EM ADMINISTRAÇÃO, 25ㅇ, 2001, Campinas. ENANPAD, Resumo dos Trabalhos: Rio de Janeiro. Metrópole

MEISTER, J. C. Educação corporativa. São Paulo: Makron Books, 1999.

O’MALLEY, J. Students perceptions of distance learning, Online learning and the tradirional classroom. Online journal of distance learning administration, Vol. II, Number IV, Winter 1999.

PILATI, R.: História e importância de TD\&E. In: BORGES-ANDRADE; ABBAD, G. S..; MOURÃO, L. (Org.). Treinamento, desenvolvimento e educação em organizações e trabalho: fundamento para a gestão de pessoas. Porto Alegre: Artmed, 2006.

RICHARDSON, R. J. Pesquisa social: métodos e técnicas. São Paulo. Atlas, 1999.

SANTOS, E. A.. Educação corporativa natura: uma experiência de formação de pessoas. Dissertação (Mestrado em Educação) - Universidade de Brasília, Brasília, 2007. 
SENGE, P.M. A Quinta Disciplina: arte e prática da organização que aprende. São Paulo: Best Seller, 2002.

VARGAS, M. R.: Treinamento e desenvolvimento: reflexões sobre seus métodos. Revista de Administração. São Paulo. v.31. n. 2. p.126-136, abr./jun. 1996.

. Educação a Distância e Mudança Organizacional: uma análise do novo modelo de treinamento e desenvolvimento de pessoal nas organizações do século XXI. 2002. $154 \mathrm{f}$. Projeto de Qualificação (Doutorado em Psicologia) - Instituto de Psicologia, Universidade de Brasília, Brasília.

- Universidade Corporativa: diferentes modelos de configuração. Revista de Administração. São Paulo. v.38. n. 4. p.373-379, out./nov.dez. 2003.

Barreiras à implantação de programas de educação e treinamento a distância. 2004. Tese (Doutorado em Psicologia) - Instituto de Psicologia, Universidade de Brasília, Brasília.

VARGAS, M. R.; ABBAD, G. S. Bases conceituais em treinamento, desenvolvimento e educação - TD\&E. In: BORGES-ANDRADE; ABBAD, G. S..; MOURÃO, L. (Org.). Treinamento, desenvolvimento e educação em organizações e trabalho: fundamento para a gestão de pessoas. Porto Alegre: Artmed, 2006.

VERGARA, S. C. Começando a definir a metodologia. In: Projetos e relatórios de pesquisa em Administração. São Paulo. Atlas, 2007. 


\section{APÊNDICE “A” - Roteiro de Entrevista}

1) Em 2007 foi instituída a Educação Corporativa do Superior Tribunal de Justiça. Na sua opinião, que mudanças ocorreram em relação às ações de treinamento, desenvolvimento e educação?

2) Você acha que com o modelo de Educação Corporativa está havendo mais oportunidades de participar de ações de capacitação?

3) Que sugestões de melhoria você daria ao Tribunal para as ações de treinamento, desenvolvimento e educação?

4) O que você acha da modalidade de Educação a Distância como forma complementar para as ações de treinamento, desenvolvimento e educação? 


\section{ANEXO A - Questionário aplicado aos servidores do STJ ocupantes de cargos comissionados em Gabinetes de Ministro e Presidência}

\section{PESQUISA SOBRE ACEITAÇÃO DA EDUCAÇÃO A DISTÂNCIA}

\section{Caro (a) Colega,}

Esta pesquisa faz parte da monografia de final de curso de especialização em Gestão Judiciária realizada na Universidade de Brasília, cujo tema é: VIABILIDADE DE IMPLANTAÇÃO DE UM MODELO DE UNIVERSIDADE CORPORATIVA NO PODER JUDICIÁRIO e tem por objetivo avaliar o nível de aceitação da Educação a Distância como modalidade para realização de ações de treinamento, desenvolvimento e educação no STJ.

Conto com sua valiosa contribuição para responder a este questionário. Para tanto, leia com atenção as considerações que seguem:

- As suas respostas serão analisadas de forma conjunta, não permitindo sua identificação.

- Não há resposta certa ou errada. Por favor, responda TODAS as questões. A qualidade dos resultados dependerá do seu empenho em responder com precisão e cuidado.

- Leia atentamente as questões e avalie, individualmente, o quanto cada uma delas descreve o que você pensa em relação à afirmativa.

Agradeço antecipadamente sua colaboração.

Herminia Lúcia Santos de Oliveira

herminia@stj.jus.br

Telefone: 84456043

Orientações para preencher o questionário

- Por favor, para cada uma das questões colocadas na coluna da esquerda, faça um "X" na coluna da direita embaixo do número que melhor represente a sua opinião.

- A escala abaixo mostra o que significa cada número:

$1=$ discordo totalmente da afirmativa

2 = discordo um pouco da afirmativa

3 = não concordo nem discordo da afirmativa
4 = concordo um pouco com afirmativa

$\mathbf{5}=$ concordo totalmente com a afirmativa

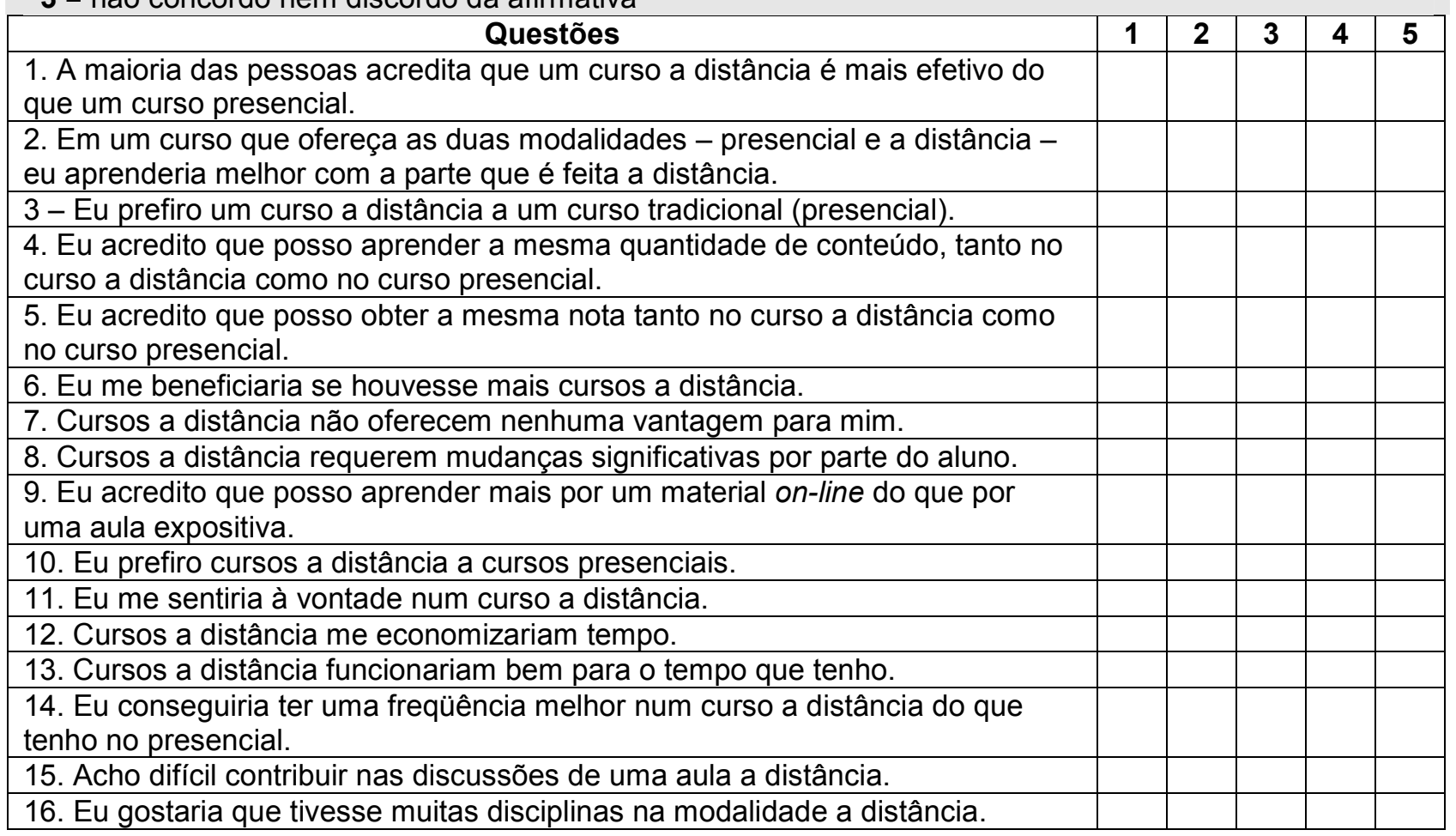

(C) O’Malley (1999) 


\section{Informações Gerais}

POR FAVOR, para finalizar responda aos itens a seguir. Eles são importantes para o tratamento estatístico dos dados da pesquisa.

\begin{tabular}{|c|c|}
\hline ( ) Feminino & asculino \\
\hline $\begin{array}{l}\text { Faixa etária } \\
\text { ( ) menos de } 25 \text { anos } \\
\text { ( ) } 25 \text { a } 35 \text { anos } \\
\text { ( ) } 36 \text { a } 45 \text { anos } \\
\text { ( ) } 46 \text { a } 55 \text { anos } \\
\text { ( ) acima de } 55 \text { anos }\end{array}$ & $\begin{array}{l}\text { Estado civil } \\
\text { ( ) casado } \\
\text { ( ) solteiro } \\
\text { ( ) viúvo } \\
\text { ( ) separado } \\
\text { ( ) divorciado } \\
\text { ( ) outro }\end{array}$ \\
\hline $\begin{array}{l}\text { Escolaridade } \\
\text { ( ) Ensino Fundamental }\left(1^{\circ} \mathrm{grau}\right) \\
\text { ( ) Ensino médio }\left(2^{\circ} \mathrm{grau}\right) \\
\text { ( ) Superior incompleto } \\
\text { ( ) Superior } \\
\text { ( ) Especialização incompleta } \\
\text { ( ) Especialização } \\
\text { ( ) Mestrado incompleto } \\
\text { ( ) Mestrado } \\
\text { ( ) Doutorado incompleto } \\
\text { ( ) Doutorado }\end{array}$ & $\begin{array}{l}\text { Lotação } \\
\text { ( ) Área Judiciária } \\
\text { ( ) Área Administrativa }\end{array}$ \\
\hline $\begin{array}{l}\text { Tempo de exercício no Tribunal } \\
\text { ( ) menos de } 1 \text { ano } \\
\text { ( ) } 1 \text { a } 5 \text { anos } \\
\text { ( ) } 6 \text { a } 10 \text { anos } \\
\text { ( ) } 11 \text { a } 15 \text { anos } \\
\text { ( ) } 16 \text { a } 20 \text { anos } \\
\text { ( )Mais de } 20 \text { anos }\end{array}$ & $\begin{array}{l}\text { Tipo de vínculo com a Organização } \\
\text { ( ) Servidor ocupante do cargo de Analista Judiciário } \\
\text { ( ) Servidor ocupante do cargo Técnico Judiciário } \\
\text { ( ) Servidor Requisitado } \\
\text { ( ) Servidor sem vínculo com a Administração Pública } \\
\text { ( ) Servidor em Exercício Provisório }\end{array}$ \\
\hline $\begin{array}{l}\text { Ocupa cargo/função comissionada } \\
\text { ( ) Não } \\
\text { ( ) FC-2 } \\
\text { ( ) FC-4 } \\
\text { ( ) FC-5 } \\
\text { ( ) FC-6 } \\
\text { ( ) CJ-1 } \\
\text { ( ) CJ-2 } \\
\text { ( ) CJ-3 } \\
\text { ( ) } \mathrm{CJ}-4\end{array}$ & $\begin{array}{l}\text { Tempo de cargo/função comissionada } \\
\text { ( ) Não ocupo cargo/função comissionada } \\
\text { ( ) menos de } 1 \text { ano } \\
\text { ( ) de } 1 \text { a } 3 \text { anos } \\
\text { ( ) de } 4 \text { a } 6 \text { anos } \\
\text { ( ) de } 7 \text { a } 9 \text { anos } \\
\text { ( ) de } 10 \text { a } 12 \text { anos } \\
\text { ( ) de } 13 \text { a } 15 \text { anos } \\
\text { ( ) de } 16 \text { a } 18 \text { anos } \\
\text { ( )Mais de } 18 \text { anos }\end{array}$ \\
\hline
\end{tabular}




\title{
ANEXO B - Portaria que institui os programas de aprendizagem da Educação Corporativa STJ
}

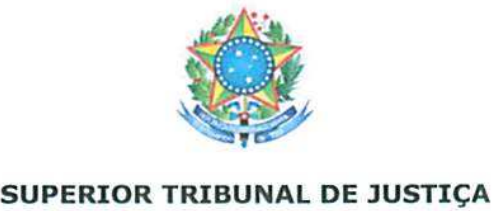

PORTARIA N. 25, DE 28 DE FEVEREIRO DE 2007

\author{
Institui os programas de aprendizagem que \\ integram a Educação Corporativa do Superior \\ Tribunal de Justiça.
}

O DIRETOR-GERAL DA SECRETARIA DO SUPERIOR TRIBUNAL DE JUSTIÇA, no uso da competência delegada pelo art. 10, I, do Ato no 88 , de 15 de abril de 2004 ,

\section{RESOLVE:}

Art. $1^{\circ}$ A Educação Corporativa do Superior Tribunal de Justiça tem como propósito gerar processos de aprendizagem que impulsionem o cumprimento da Missão e a realização das Estratégias da Administração.

Art. $2^{\circ}$ São objetivos da Educação Corporativa do ST]:

I - Comprometer, permanentemente, as pessoas com a Visão, Missão e Valores do Tribunal;

II - Alinhar as ações de educação às Estratégias da Administração;

no futuro;

III - Desenvolver as competências necessárias à organização no presente e resultados almejados;

IV - Estabelecer conexão entre os processos de aprendizagem e os

V - Fomentar a ação educativa em todos os níveis da organização e estendê-la a clientes, fornecedores e parceiros externos;

VI - Compartilhar conhecimentos e experiências existentes na organização;

VII - Integrar os processos de educação corporativa com todos os processos e ferramentas de gestão de pessoas;

Tribunal.

VIII - Estimular a co-responsabilidade no processo de educação no

Art. 30 A Educação Corporativa do STJ é composta por programas de aprendizagem, na forma apresentada no Anexo desta Portaria, estruturados em vertentes e destinados ao desenvolvimento de competências, habilidades e valores necessários à excelência dos serviços prestados pelo Tribunal.

Art. $4^{\circ}$ Esta Portaria entra em vigor na data de sua publicação.

MIGUEL AUGUSTO FONSECA DE CAMPOS

Diretor-Geral 


\section{ANEXO C - Anexo da Portaria que institui os programas de aprendizagem da Educação Corporativa STJ}

ANEXO

VERTENTES E PROGRAMAS DE APRENDIZAGEM PREVISTOS NA EDUCAÇÃO CORPORATIVA DO STJ

I - Vertente Cidadania Organizacional - destina-se a promover a compreensão e o engajamento das pessoas com a missão e a visão do Tribunal e, ainda, com a prática dos valores institucionais. Compõem-se dos seguintes programas:

a) STJ - Um Referencial de Excelência

b) Praticando Valores

c) Sintonia Organizacional

d) InovaAção

e) Expandindo Fronteiras de Aprendizagem

II - Vertente Estratégica - busca desenvolver as competências necessárias à execução dos objetivos e projetos estratégicos, tanto no contexto atual como nas oportunidades futuras visualizadas pela organização, compreendendo os seguintes programas:

a) Agilizando os Caminhos Processuais

b) Integrando o Sistema ST]

c) Análise Processual e Efetividade Jurídica

d) Bem Servir, Bem Atender

e) Melhoria Tecnológica

III - Vertente Funcional - prepara o servidor para torná-lo eficaz no desempenho das atividades que executa no dia-a-dia do trabalho. Subdivide-se em dois segmentos - Gerencial e Técnico.

a) Segmento Gerencial: composto de três programas que objetivam desenvolver competências gerenciais:

i.Planejando e Gerindo o Alto Desempenho

ii. Mobilizando Pessoas

iii.Conduzindo Melhorias

b) Segmento Técnico: desenvolve os conhecimentos e habilidades fundamentais para a execução das atividades específicas de cada unidade do Tribunal. 
ANEXO D - Folder de divulgação da Educação Corporativa STJ

Faça parte de um ambiente de trabalho mAis...

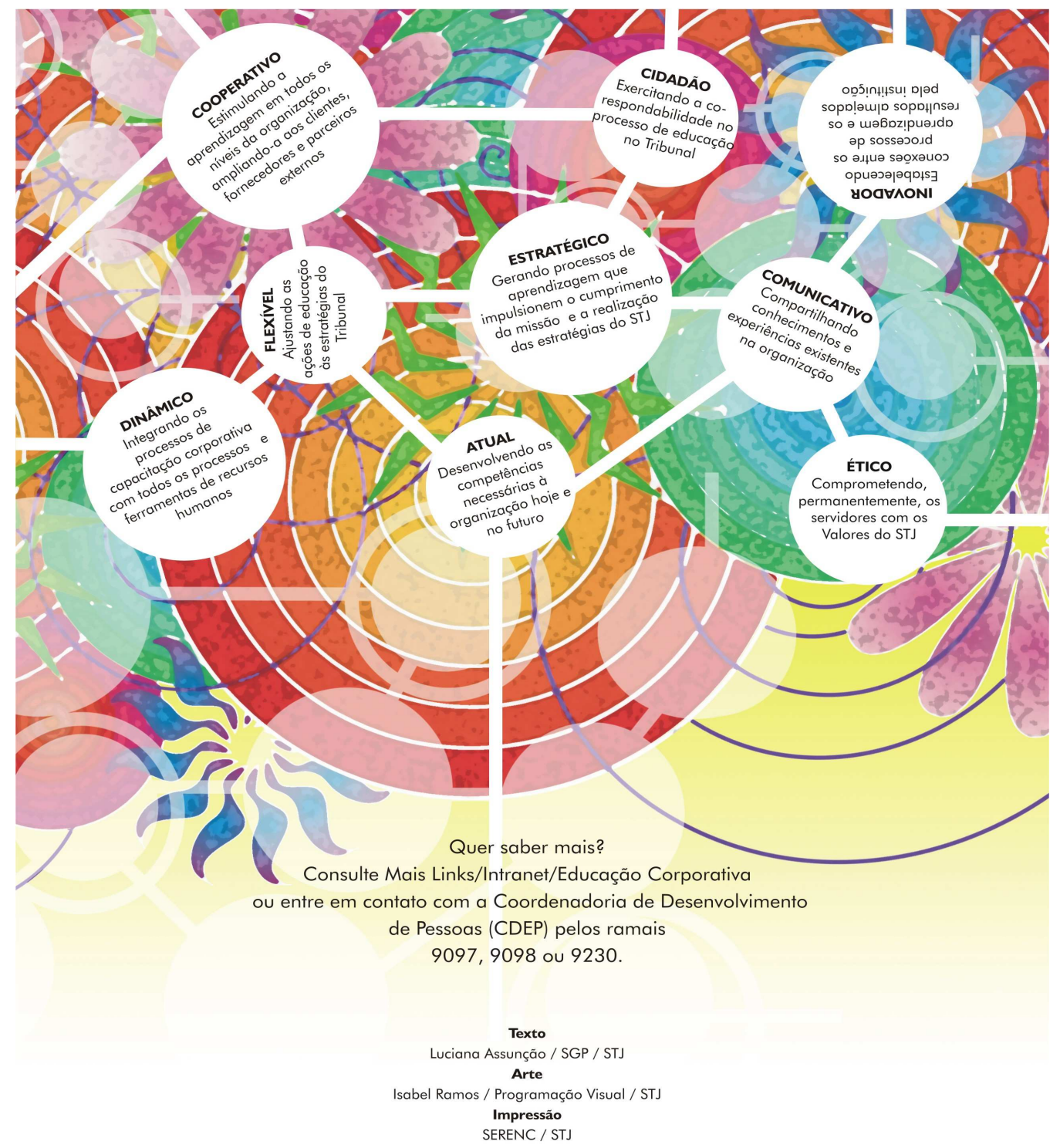


Porque você é:

O principal responsável por seu processo formativo, participando da ação que gera o próprio CRESCIMENTO e o desenvolvimento da nossa instituição;

A PESSOA que faz a diferença ao lidar com os desafios profissionais, pois detém conhecimentos e capacidade que aprimoram os serviços prestados pela Casa;

O agente de mudanças e de RESULTADOS que constroem a boa imagem do Tribunal perante a sociedade brasileira.

\section{Faça parte do modelo de Educação Corporativa}

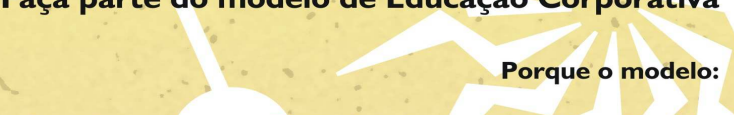

- Contribui para a EFETIVIDADE dos serviços prestados pelo

Tribunal à sociedade;

- Considera a competência como o conjunto de conhecimentos, habilidades e ATITUDES que gera resultados para a organização;

- Cria formas diversificadas de APRENDIZAGEM (treinamento em serviço, treinamento via , mapas de informação, discussões das ESTRATÉGIAS institucionais:

- Amplia o compartilhamento das responsabilidades entre a pessoa, o gerente e a área de GESTÃO DE PESSOAS

- Democratiza o ACESSO ao conhecimento, por meio de recursos de - educação fora da "sala-de-aula";

- Valoriza o papel do servidor como gestor de sua própria CARREIRA - Favorece a mobilização e a integração entre os gerentes e suas EQUIPES em relação às metas de aprendizagem;

Desenvolve a excelência HUMANA e profissional dos participantes.

\section{Espaços de Atuação da Educação Corporativa - Vertentes}

- Cidadania Organizacional: programas de educação voltados para trabalhar a Missão, Visão e Valores da Instituição;

- Estratégica: capacitação voltada para o alcance dos objetivos estratégicos da Casa;

- Funcional: atualização profissional voltada para o exercício das atividades no posto de trabalho. 